\author{
FINAL REPORT \\ PROJECT 3.1 - PROCESS CONEIGURATIONS/MODELING \\ submitted to \\ Ohio Coal Research Consortium \\ December 31, 1993 \\ Project Duration: $9 / 1 / 92$ through $11 / 30 / 93$ \\ Department of Chemical Engineering \\ Ohio University \\ Athens, Ohio 45701 \\ Kendree J. Sampson \\ Michael E. Prudich \\ Dale W. Duespohl
}

\title{
RECEIVED
}

MAY 061994

DEPARTMENT OF DEVELOPMENT

OHD COAL DEV OFFICE

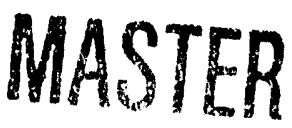

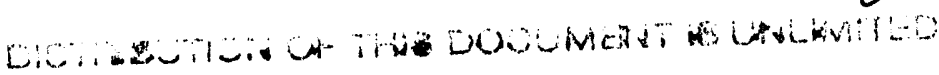




\section{TABLE OF CONTHETS}

Executive Summary. . . . . . . . . . . . . . . . . . . . . . I

Introduction. . . . . . . . . . . . . . . . . . . . . . 1

Accomplishments . . . . . . . . . . . . . . . . . . . . 1

Conclusions . . . . . . . . . . . . . . . . . . . . . . 3

Introduction . . . . . . . . . . . . . . . . . . . . . . . . 4

Task I-A: Transfer to Supercomputer . . . . . . . . . . . . 4

Vectorization...................... . 4

Adaptive Grid . . . . . . . . . . . . . . . . . . . . . 5

Task I-3: Upgrade Kinetic Models. . . . . . . . . . . . . . 5

Resistance-In-Series Model. . . . . . . . . . . . . . . 5

Dry Capture Model . . . . . . . . . . . . . . . . . . . 12

Precipitate Blinding Model. . . . . . . . . . . . . . . 14

Task I-C: Regeneration/Recycle Model. . . . . . . . . . . . 17

Mass Balances . . . . . . . . . . . . . . . . . . . . . 17

Costing . . . . . . . . . . . . . . . . . . . . . . . 20

Task II-A: Optimization Algorithm . . . . . . . . . . . . . 21

Task II-B: Program Runs . . . . . . . . . . . . . . . . . . 22

Design Basis. . . . . . . . . . . . . . . . . . . . . . 22

Evaluation of the Adaptive Grid . . . . . . . . . . . . 24

Simulation Results. . . . . . . . . . . . . . . . . 25

Nomenclature . . . . . . . . . . . . . . . . 27

References . . . . . . . . . . . . . . . . . . . . . 41

Appendix - Simulation Results. . . . . . . . . . . . . . . . 42 
EXECUTIVE SUMOMARY

\section{Introduction}

The objective of this research is to develop and optimize preliminary process designs and cost estimates for a moving bed granular limestone desulfurization process typified by the LEC process.

The basic simulation programs have been written, debugged, and used to simulate the operation of a desulfurization plant with a cross flow moving bed configuration. The programs are based on first principles type mathematical models which reflect the underlying transport and chemical reactions which are involved in the desulfurization process. Spatial and temporal variations in component concentrations and temperature are considered. The simulation program centers around a resistance in series model which is used to calculate the sulfur dioxide transport rate. Resistances include mass transfer from the bulk gas to the condensed liquid surface, diffusion of sulfate and calcium ions in the liquid layer, and dissolution of calcium ions from the limestone surface. Sorbent blinding due to the formation of a precipitate layer and dry capture have also been incorporated into the model.

\section{Accomplishments}

The response to specific items in the third year statement of work is summarized below.

Task I-A: Transfer to supercomputer. The simulation program has been transferred from the Ohio University VAX 6440 to the Ohio Supercomputer Cray Y-MP8 located in Columbus, Ohio. Minor code modifications were made to compensate for the differences between the VAX and the Cray FORTRAN compilers.

By itself, the change of computers resulted in only a modest increase in computation power. A test comparison on an identical simulation run required 75 minutes of CPU time on the Cray and 275 minutes of CPU time on the VAX. (As a further point of reference, the VAX 6440 runs typical FORTRAN code at about the same rate as a $486 / 50$ PC.)

The main advantage in using the supercomputer comes from the application of code vectorization. This step required more extensive changes to create an algorithm and code which is "vectorizable." The ccie optimization step was very successful. The optimized code runs at about 100 Mflops while the unoptimized code runs at about 10 Mflops.

To further reduce the simulation time, the numerical method was improved by incorporating an adaptive grid. This shortens 
the simulation time by reducing the number of calculations required. In practice, this change reduces the computation time required by another factor of two.

The combined effect of the three changes described above is a reduction in the computational requirements by a factor of about one hundred.

Task I-B: Uparade Kinetic Models. The previous threeresistance-in-series-model which was originally developed by Visneski et al. [1] has been extended to include the effects of $\mathrm{CaSO}_{3} / \mathrm{CaSO}_{4}$ precipitate layer blinding and dry sorbent capture.

The blinding model idealizes the sorbent surface by segregating it into blinded and non-blinded regions. The precipitate layer extends vertically above the blinded surfaces. The blinded surface area gradually increases until the entire sorbent is unreactive. This model requires a single additional parameter which can be established by noting the extent of reaction at the point of complete blinding.

A dry sorbent capture model has been developed which mimics the behavior observed experimentally by Klingspor et al. [2] and as a part of this research. The term "dry sorbent capture" refers to the situation where a bulk liquid phase is not present on tha surface of the sorbent. The distinction is made carefuliy because Klingspor et al. [2] indicates that several "monolayers" of adsorbed water vapor on the limestone surface are required for the reaction to occur. This model is consistent with the observed strong dependence of the reaction rate on the gas phase humidity.

The present model reproduces this behavior by allowing reaction to occur in a zero thickness liquid film which partially covers the sorbent surface. An empirical relationship between the fractional liquid coverage and the relative gas humidity is required.

It is also assumed that the water on the surface of the sorbent is divided into areas wich are small compared to the gas film thickness. This enables us to consider the transport in the gas to be a one-dimensional diffusion process with a step change in the transport area occurring at the gas-liquid interface.

Task I-C: Regeneration/Recvcle Model. As a result of the upgrades to the kinetic models, solid sulfur concentrations are available within the simulation. This allows a more detailed material balance to be used to follow the benavior of the sorbent regeneration and recycle. An empirisal equation which describes the operation of the screen separating Caso, fines from unreacted sorbent has been developed and included in the simulation. 
Task II-A: Optimization Algorithm. Although this task is not listed in the original statement of work, considerable effort has been expended developing an optimization algorithm for the desulfurization plant. There are nine independent design parameters which must be specified as part of the optimization process. Three can be determined by inspection. Two are optimized during the course of a single numerical solution to the governing material and energy balances. The remaining four remain to be solved as an unconstrained nonlinear optimization problem. A quasi-Newton method available on the Cray computer has been adopted for this purpose.

The optimization algorithm has not been developed to the point where the search leads to a reasonable solution. Therefore the goals of the original statement of work have not been fully met. It is currently expected that the problem lies in the cost model for the desulfurization plant and that further refinements in this model will enable the optimization search to find appropriate solutions.

Task II-B: Program Runs, Because the optimization algorithm is not yet in full operation, optimum results cannot be reported at this time. Instead, representative results for each of the design cases in the original statement of work are included in this report. report.

Task III: Final Report. This requirement is met by this

\section{Conclusions}

The desulfurization plant simulation is fully developed and available on a platform which makes it convenient to use in detailed studies. The new model features included this year complete the list of features which are desirable and reasonable to be included. Further refinemencs in the model structure are not warranted. Of course, refinements in model parameters would always be desirable.

The optimization studies have not been completed. However the algorithm is in place and further development will be confined to changes in the cost model only. Potential problems are not expected to pronibit completion of this work. 


\section{INTRODUCTION}

The following report is incended as a sequel to year one Ohio Coal Research Consortium final report for this project [3] and to the work of Chattopadhyay [4]. As such, these references should be consulted for detailed explanarions of the basic modeling assumptions and equations used in the simulation code.

This report contains a detailed description of modeling developments completed in the third year of the consortium. (Note that the project did not participate in the second year of the consortium.) This is followed by a presentation and discussion of simulation results.

\section{TASK I-A: TRANSFER TO SURERCOMPUTER}

\section{Vectorization}

The primary advantage of using a supercomputer such as the Cray Y-MP8 is the ability to vectorize the code. The complete details of the steps needed to accomplish this task are probably not of general interest. However, a few comments regarding the modifications may be appropriate.

The only portions of code which can be vectorized are those which have no loops, subroutine calls, conditional branch points, or data dependencies. The CF77 compiler available on the Y-MP8 has automatic routines to "unwind" loops into explicit code and to "in-line" subroutines by copying the entire subroutine into each point where it is referenced in the calling program. The first two concerns can therefore be solved routinely. However, the number of loop passes must be fixed and this is inconsistent with the normal practice of using a convergence criterion to terminate an iterative calculation within the numerical procedure. A fixed number of iterations must be used and the convergence assured by independent testing. The unvectorized code was based on a Modified Euler's or Predictor-Corrector algorithm which normally requires a convergence test to establish the number of corrector steps. The number of corrector steps was fixed at one in the vertorized code.

The problem of data dependencies was somewhat more troublesome in this application. The basic numerical algorithm used in the reactor bed simulations is an analogue to Euler's method adapted for use in a problem with two independent variables, namely vertical ( $y$ ) and horizontal $(x)$ directions in the bed. An iterative solution is required where the solution at any point $\left(x_{i}, y_{j}\right)$ depends on the solution at points $\left(x_{i-1}, y_{j}\right)$ and $\left(x_{i}, y_{i-1}\right)$. This structure normally prohibits vectorization of the computer code because the calculation of values for any row or column of grid points requires knciledge of other elements in the 
same row or column before the calculation can proceed.

The problem has been circumvented by forcing the code to work along diagonal rows of grid elements within the rectangular array of grid elements in the $x$ and $y$ directions. An example of such a row would be the set of elements $\left(x_{i}, y_{j}\right),\left(x_{i+1}, y_{j-1}\right)$, $\left(x_{i+2}, y_{j-2}\right)$, etc. The solution for this set of elements depends on the solution for elements in the previous diagonal row but not on other elements in the same row. The solution for the set of elements in a diagonal row can therefore be vectorized.

\section{Adaptive Grid}

The reactor simulation problem can be characterized as a stiff set of differential equations in the sense that large changes in the dependent variables occur in the vicinity of the drying front while other areas of the sorbent bed are relatively uniform. A very small grid size is needed to provide accuracy and stability in the numerical algorithm in the vicinity of the drying front; however this fine mesh represents a waste of computational resources in other areas.

To solve this problem, the complete set of grid elements has been divided into an array of large grid elements which collectively fill the entire solution domain. The purpose of this structure is to allow for a variable mesh size from one large grid element to the next. This adaptive grid allows for a large numerical step size when the gradients in the bed are small, and automatically changes to a small step size when the gradient becomes steep.

The solution through a series of diagonal rows is confined within a single block at any given time. The solution is transferred between neighboring blocks of different mesh sizes by interoolation or deletion of unneeded points as appropriate.

\section{TASR I-B: OPGRADE RINETIC MODELS.}

\section{Resistance-In-Series Model}

The following text describes the expressions for calculating the $\mathrm{SO}_{2}$ transport rate and reaction front position. This development builds upon the earlier three-resistance-in-series model [1] (gas phase $\mathrm{SO}_{2}$ transport, liquid phase $\mathrm{SO}_{3}{ }^{-}$and $\mathrm{Ca}^{++}$ transport, and Ca dissolution) by including the effects of precipitate layer blinding and dry sorbent capture.

Extensions related to the precipitate blinding effect include the following provisions or assumptions. The precipitate layer blinds a fraction of the surface and renders it nonreactive. The fraction proceeds from zero to one as the reaction 
progresses.

Transport in the portion of the surface which is not blinded proceeds as if the precipitate layer is not present. However the thickness of the liquid layer must be adjusted to account for the precipitate layer which coexists with the liquid on the surface of the sorbent pellets. This effect is described in Figure 1. The thickness of the precipitate layer, $\delta_{p}$, is calculated by dividing the volume of precipitate by the blinded surface area. The thickness of the liquid layer, $\delta_{1}$, is tentatively calculated by dividing the volume of liquid by the non-blinded surface area. If $\delta_{\text {: }}$ is greater than $\delta_{p}$ the value of $\delta_{1}$ must be recalculated recognizing that the surface area above the precipitate layer is equal to the total sorbent surface.

It is also assumed that the thickness of each blinded portion of the sorbent in the direction along the sorbent surface (the vertical direction in Figure 1) is much lower than $\delta_{1}$ or $\delta_{p}$. (Figure 1 is therefore not to scale.) This enables us to consider the transport in the liquid to be a one-dimensional diffusion process with a step change in the transport area occurring at the top surface of the precipitate layer.

Explicit expressions for the $\mathrm{SO}_{2}$ transport rate are found by solving a set of rate expressions which give the transport rate through each of the resistance layers. Intermediate concentrations are algebraically eliminated from the rate expressions leaving a final result expressed in terms of the bulk gas phase $\mathrm{SO}_{2}$ concentration, $\mathrm{C}_{\mathrm{sg}}$, and the $\mathrm{Ca}^{++}$solubility in the liquid phase, $C_{\text {ele }}$.

The model continues to use an instantaneous reaction assumption to describe the byproduct formation

$\mathrm{Ca}++\mathrm{SO}_{3}{ }^{+-}-->\mathrm{CaSO}_{3}$

The location of the reaction front must be calculated as an intermediate result prior to decermining the $\mathrm{SO}_{2}$ transport rate. The strategy used to complete the calculation is to guess in which region the reaction front lies and then calculate the location of the reaction front using the appropriate rate expressions for the individual resistance layers. If the calculated position is outside the guessed region the calculation must be repeated using the correct region.

Detailed derivations are given below for eight distinct cases. Cases I-A, I-B, I-C, and I-D are for the situation where the liquid layer extends above the precipitate layer. Cases II$A, I I-3$, and II-C are for the situation where the liquid layer does not extend above the precipitate layer. Case III considers dry sorbent capture. For Cases $I-A$ and $I I-A$ the reaction front coincides with the liquid-gas interface and the reaction is gas 


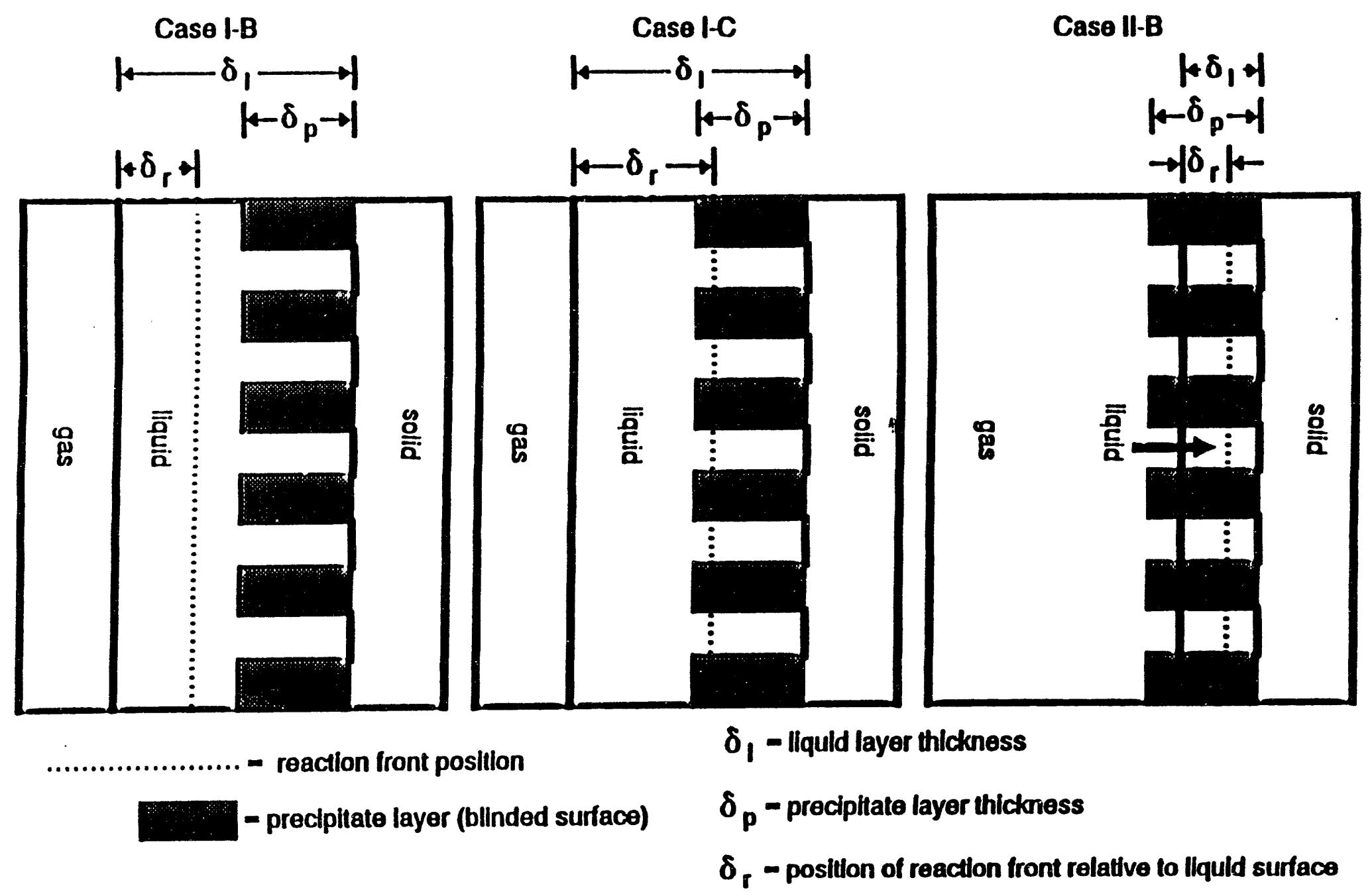

Figure 1. Schematic representation of blinding model. 
Frase controlled. For Case $I-B$ the reaction front is in the I: ruid layer above the precipitate layer. For Case I-C and II-B to: reaction front is in the liquid layer coexisting with the precipitate layer. For Case I-D and II-C the reaction front ccincides with the liquid-solid interface and the reaction is dissolution controlled.

Cä;e I-A

$$
\delta_{1}>\delta_{p}
$$$$
\delta_{\Sigma}=0
$$

For the case of gas phase control and a liquid layer extending above the precipitate layer the final transport expression can be written down immediately. Note that the interfacial concentration, $C_{s g i}$, is zero.

$$
g_{s}=k_{s s} a_{m g} c_{s g}
$$

Herr, $g$, is the sulfur dioxide transport rate, $k_{\text {ma }}$ is the gas phaise mass transfer coefficient, $a_{\text {mg }}$ is the area for mass transfer in the gas phase, and $\mathrm{C}_{s g}$ is the concentration of $\mathrm{SO}_{2}$ in the zas phase.

Case I-B $\delta_{1}>\delta_{p} \quad \delta_{1}-\delta_{p}>\delta_{x}>0$

In this case five expressions for the $\mathrm{SO}_{2}$ transport rate must be solved simultaneously along with the gas-liquid equilibrium relationship.

$$
\begin{aligned}
& g_{s}=k_{s s} a_{m g}\left(C_{s g}-C_{s g i}\right) \\
& =D_{s 1} a_{11} C_{s 1 i} / \delta_{x} \\
& =D_{c 1} a_{71} C_{c_{p}} /\left(\delta_{1}-\delta_{p}-\delta_{z}\right) \\
& =D_{z=2} a_{p p}\left(C_{z=19}-C_{s 1 p}\right) / \delta_{0} \\
& =k_{m c} a_{p g}\left(C_{c 1 e}-C_{c 1 s}\right) \\
& C_{s g i}=H_{s} C_{s i i} \rho_{g} / P=C_{s i_{1}}\left(H_{s} / R T_{g}\right)
\end{aligned}
$$

Here $D_{41}$ is the diffusivity of $\mathrm{SO}_{3} \ldots$ ions in the liquid phase, $a_{31}$ is the area for mass transfer in the liquid phase, $C_{s i i}$ is the concentration of $\mathrm{SO}_{3}-$ at the liquid interface, $\mathrm{D}_{\mathrm{Cl}}$ is the diffusivity of $\mathrm{Ca}++$ ions in the liquid phase, $\mathrm{C}_{\mathrm{clo}}$ is the concentration of $\mathrm{Ca}++$ ions at the outer edge of the precipitate layer, $a_{m p}$ is the area for mass transfer in the precipitate layer, $\mathrm{C}_{21 \mathrm{~s}}$ is the concentration of $\mathrm{Ca}++$ at the unreacted sorbent surface, $k_{m c}$ is a psuedo mass transfer coefficient used to describe the dissolution process, $C_{e s .}$ is the solubility of $C a$ in the liquid, $\mathrm{H}_{s}$ is a Henry's law constant for $\mathrm{SO}_{2,} \rho_{g}$ is the gas phase dunsity, $P$ is pressure, $R$ is the ideal gas constant, and $T_{3}$ is the yas phase temperature. Simultaneous solution of these 
equations gives the transport rate

$$
g_{s}=\frac{C_{s g}}{\frac{1}{k_{m s} a_{m g}}+\frac{\delta}{D_{s 1} a_{m l}\left(R T_{g} / H_{s}\right)}}=\frac{C_{c l e}}{\frac{\delta_{1}-\delta_{f}-\delta_{j}}{D_{c 1} a_{m l}}+\frac{\delta_{p}}{D_{c 1} a_{m p}}+\frac{1}{k_{m c} a_{m p}}}
$$

and the location of the reaction front

$$
\delta_{I}=\frac{\frac{\delta_{1}-\delta_{p}}{D_{c 1} a_{m 1} C_{c l e}}+\frac{\delta_{p}}{D_{c 1} a_{m p} C_{c l e}}+\frac{1}{k_{m c} a_{m p} C_{c l e}}-\frac{1}{k_{m s} a_{m g} C_{s g}}}{\frac{1}{D_{s 1} a_{m l} C_{s g}\left(R T_{g} / H_{s}\right)}+\frac{1}{D_{c l} a_{m l} C_{c l e}}}
$$

If the calculated value of $\delta_{y}$ is less than zero then the reaction is gas phase controlled and Case I-A must be used. If the calculated value of $\delta_{=}$is greater than $\delta_{1}-\delta_{p}$ then the reaction front is in the precipitate layer or the reaction is dissolution rate controlled and Case I-C or I-D must be used.

Case I-C $\delta_{1}>\delta_{\mathrm{p}} \quad \delta_{1}>\delta_{2}>\delta_{1}-\delta_{\mathrm{p}}$

This case is the same as Case I-B except that the reaction front is within the precipitate layer.

$$
\begin{aligned}
& g_{s}=k_{s s} a_{g g}\left(C_{s g}-C_{s g i}\right) \\
&=D_{s 1} a_{m 1}\left(C_{s 1 i}-C_{s 1 p}\right) /\left(\delta_{1}-\delta_{p}\right) \\
&=D_{s 1} a_{m p} C_{s 1 p} /\left(\delta_{s}-\delta_{1}+\delta_{p}\right) \\
&=D_{s:} a_{m p} C_{c 1 s} /\left(\delta_{1}-\delta_{s}\right) \\
&=k_{m c} a_{m p}\left(C_{s: s}-C_{s ! s}\right) \\
& C_{s q 1}=E_{s} C_{s 1 i} \rho_{g} / P=C_{s 1 i}\left(H_{s} / R T_{g}\right)
\end{aligned}
$$

Here $\mathrm{C}_{\mathrm{sip}}$ is the concentration of $\mathrm{SO}_{3}-$ - ions at the surface of the precipitate layer. Simultaneous solution of these equations gives the transport rate

$$
g_{s}=\frac{C_{s q}}{\frac{1}{k_{m s} a_{m g}}+\frac{\delta_{1}-\delta_{c}}{D_{s 1} a_{m l}\left(R T_{g} / H_{s}\right)}+\frac{\delta_{z}-\delta_{1}+\delta_{p}}{D_{s 1} a_{m p}\left(R T_{g} / H_{s}\right)}}=\frac{C_{c l e}}{\frac{\delta_{1}-\delta_{z}}{D_{c 1} a_{m p}}+\frac{1}{k_{m c} a_{m p}}}
$$

and the reaction front location 


$$
\delta_{=}=\frac{\frac{\delta_{1}}{D_{c 1} a_{m p} C_{C 1 e}}+\frac{1}{k_{m c} a_{m p} C_{C 1 e}}-\frac{1}{k_{m s} a_{m g} C_{s g}}-\frac{\delta_{1}-\delta_{p}}{D_{s 1} a_{m 1} C_{s g}\left(R T_{g} / H_{s}\right)}-\frac{1}{D_{s 1} a_{m p} C_{s g}\left(R T_{g} / H_{s}\right)}}{\frac{1}{D_{s 1} a_{m p} C_{s g}\left(R T_{g} / H_{s}\right)}+\frac{1}{D_{c 1} a_{m p} C_{c l e}}}
$$

If the calculated value of $\delta_{x}$ is less than $\delta_{1}-\delta_{p}$ then the reaction front is above the precipitate layer or the reaction is gas phase controlled and Case I-A or I-B must be used. If the calculated value of $\delta_{y}$ is greater than $\delta_{1}$ then the reaction is dissolution rate controlled and Case I-D must be used.

Case I-D $\delta_{1}>\delta_{p} \quad \delta_{y}=\delta_{1}$

For the case of dissolution rate control the transport expression can be written down immediately. Note that the concentration of calcium ions at the unreacted solid surface, $\mathrm{C}_{\mathrm{cla}, \mathrm{i}}$ is zero.

$$
g_{s} \stackrel{*}{=} k_{s c} a_{s p} c_{c 1 e}
$$

Case II-A $\delta_{\mathrm{p}}>\delta_{1} \quad \delta_{=}=0$

For the case of gas phase control and the precipitate layer extending above the liquid layer the gas phase resistance is split into two parts. Note that the interfacial concentration, $\mathrm{C}_{\mathrm{sg} \text {, }}$ is zero.

$$
\begin{aligned}
g_{s} & =k_{m s} a_{s g}\left(C_{s q}-C_{s p}\right) \\
& =D_{s q} a_{m p} C_{s p} /\left(\delta_{p}-\delta_{1}\right)
\end{aligned}
$$

Simultaneous solution of these equations gives the transport rate

$$
g_{s}=\frac{C_{s g}}{\frac{1}{k_{m s} a_{m g}}+\frac{\delta_{p}-\delta_{1}}{D_{s q} a_{m p}}}
$$

Case II-B $\delta_{\mathrm{p}}>\delta_{1} \quad \delta_{1}>\delta_{2}>0$

In this case five expression for the $\mathrm{SO}_{2}$ transport rate must be solved simultaneously along with the gas-iquid equilibrium relationship.

$$
g_{s}=k_{s s} a_{m g}\left(C_{s q}-C_{s p}\right)
$$




$$
\begin{aligned}
&=D_{s g} a_{p p}\left(C_{s p}-C_{s g i}\right) /\left(\delta_{p}-\delta_{2}\right) \\
&=D_{s 1} a_{m p} C_{s 1:} / \delta_{g} \\
&=D_{s:} a_{m p} C_{c i s} /\left(\delta_{1}-\delta_{g}\right) \\
&=k_{s c} a_{m p}\left(C_{s i e}-C_{C 1 s}\right) \\
& C_{s g:}=H_{s} C_{s 1:} \rho_{g} / p=C_{s 1 i}\left(H_{s} / R T_{g}\right)
\end{aligned}
$$

Here, $C_{S p}$ is the concentration of $\mathrm{SO}_{2}$ in the gas phase at the surface of the precipitate layer. Simultaneous solution of these equations gives the transport rate

$$
g_{s}=\frac{C_{s g}}{\frac{1}{k_{m s} a_{m g}}+\frac{\delta_{p}-\delta_{1}}{D_{s g} a_{m p}}}
$$

and the location of the reaction front

$$
\delta_{z}=\frac{\frac{\delta_{1}}{D_{c 1} a_{m p} C_{c l e}}+\frac{1}{k_{m c} a_{m p} C_{c l e}}-\frac{1}{k_{m s} a_{m q} C_{s q}}-\frac{\delta_{p}-\delta_{1}}{D_{s g} a_{m p} C_{s q}}}{\frac{1}{D_{s 1} a_{m p}\left(R T_{g} / H_{s}\right)}+\frac{1}{D_{c 1} a_{m p} C_{c_{c 1}}}}
$$

If the calculated value of $\delta$ is less than zero then the reaction is gas phase concrolled and Case II-A must be used. If the calculated value of $\delta_{\text {. }}$ is greater than $\delta_{1}$ then the reaction is dissolution rate controlled and Case II-C must be used.

Case II-C $\delta_{p}>\delta_{1} \quad \delta_{n}=\delta_{1}$

For the case of dissolution rate control the transport expression can be written down immediately. Note that the concentration of calcium ions at the unreacted solid surface, $C_{\text {sis, }}$ is zero. This case is identical to case I-D.

$$
g_{s}=k_{c} a_{p p} C_{c 1 e}
$$

Case III $\delta_{1}=0$

For the case of dry sorbent capture, the controlining resistance must be either the gas Eim or dissolution. This choice is determined by calculating both rates and accepting the lower value. The rate expressions were calculated previously. From Case II-A the rate for gas phase control is 


$$
g_{s}=\frac{C_{s g}}{\frac{1}{k_{m s} \bar{a}_{m g}}+\frac{\delta_{p}-\delta_{1}}{D_{s g} a_{m 1}}}
$$

From Case II-C the rate for dissolution control is

$$
g_{s}=k_{s c} a_{n 1} c_{c 10}
$$

Note the replacement of $a_{p p}$ with $a_{p 1}$ in the above two equations.

\section{Dry Capture Model}

The model for predicting the dry $\mathrm{SO}_{2}$ capture rate has been developed based upon the concept that only a fraction of the mass transfer area is covered by a sufficient amount of water to effect sorption. This is referred to as the effective mass transfer area and denoted here and in the code as $a_{m 1}$. It is expressed as a product of the total mass transfer in the precipitate layer area and a correction factor.

$$
a_{x 1}=E a_{p p}
$$

The factor is a function of relative humidity. Data has been extracted from the work of Klingspor et al. [2] and as part of this work [5] giving the initial reaction rate versus relative humidity. (The initial rate is required so that the effect of blinding by the precipitate layer can be neglected.) This data was used to develop an expression relating the correction factor to the relative humidity:

$$
f=\frac{(1-k) H}{1-k H}
$$

where $H$ is the relative humidity and $k$ is a constant. This form observes the conditions

and

$$
E=0 \text { when } H=0
$$

$$
f=1 \text { when } \mathrm{H}=1
$$

The value of $k$ determines the shape of the curre between these two points and is determined from experimental results. The form can be interpreted as that of an adsorption isotherm although with positive values of $k$ the shape of the curve is unusual in that the second derivative of the function is positive throughout the domain.

Experimental values for the correction factor are found by dividing the experimentally measured transport rate, $g_{s}$, by the rate calculated assuming that all of the sorbent surface area is 
effective.

$$
f=\frac{g_{s}}{k_{m c} C_{c l e} A_{m p}}
$$

Dissolution control is assumed here as it should be considering the gas phase $\mathrm{SO}_{2}$ concentration of 1000 ppm used in both sets of experiments $[2,5]$.

Klingspor et al. [2] used a particle diameter of $4.0 \cdot 10^{-4} \mathrm{~m}$, a gas temperature of $343 \mathrm{~K}$, a superficial gas velocity of $4.45 \cdot 10^{-2} \mathrm{~m} / \mathrm{sec}$, a gas phase $\mathrm{SO}_{2}$ concentration of $1000 \mathrm{ppm}$, and reported an intrinsic Iimestone density of $2720 \mathrm{~kg} / \mathrm{m}^{3}$.

Experimental and model reaction rates are given in Table 1.

Table 1. Model Results from Klingspor et al. [2].

Relative Humidity Initial Reaction Rate (omol/hr/kg)

0.00

0.24 Experimental

$0.00=$ Model with $k=0.997$

0.41

0.05

0.00

0.51

0.59

0.21

0.73

0.47

0.59

1.10

0.71

0.69

1.70

0.98

0.78

2.26

1.51

0.84

2.90

2.4

0.92

6.45

3.5

7.6

1.00

228 .

The model results use a value for $k_{\mathrm{mc}}$ of $4.7 \cdot 10^{-4} \mathrm{ft} / \mathrm{sec}$, a value for $C_{3 e}$ of $2.5 \cdot 10^{-5}$ lbmole/ft ${ }^{3}$, and particle sphericity of 0.5 along with the experimental values for particle size and density given by Klingspor et al.[1]. Table 2 gives a summary of all of the available results for the dry capcure model

\begin{tabular}{lll}
\hline Table 2. & Summary of Dry Capture Model Results. \\
Reference & Limestone & Darameter k \\
\cline { 2 - 2 } & Calcitic & 0.997 \\
{$[2]$} & Maxvilie & 0.893 \\
{$[5]$} & Mississippi & 0.866 \\
{$[5]$} & Vanport & 0.885 \\
{$[5]$} & &
\end{tabular}

The large difference between the results from the two different sources cannot be explained readily. However, the results from KIingspor [2] are most in doubt since the values of $k_{m c}$ and $C_{c l e}$ 
used in the analysis have not been verified for their limestone. The remaining three values were averaged yielding a value of $k=$ 0.88 for use in the process simulation studies.

\section{Precipitate Blinding Model}

As the reaction of $\mathrm{SO}_{2}$ with limestone proceeds, the surface of the stone becomes covered with the reaction product and acts to blind the surface. To account for this effect, an empirical equation was developed to relate the surface area to the extent of reaction.

To calculate the sulfur transport rate, $g_{a}$, both the mass transfer area within the precipitate layer and the precipitate thickness are needed. If one of these two is known along with the total concentration of precipitate, the other can be found. Unfortunately neither is known a priori, thus the need for the empirical relation. The mass transfer area is estimated as follows.

First the concentration of the precipitate in the sorbent can be found with a mass balance. The concentration is denoted $\mathrm{C}_{\mathrm{ss}}$ and is defined as moles of sulfur per volume of sorbent. The volume of precipitate is then calculated from the concentration. Once the volume is known, the surface area occupied is found by dividing the volume by the thickness. (The thickness is obtained with the empirical relation.) To get the area available for mass transfer, the area occupied by the precipitate is subtracted from the total area.

Mass Balance. Performing a mass balance for sulfur on a differential element of the reactor gives a partial differential equation for the solid sulfur concentration.

$$
\frac{\partial C_{s s} U_{s}}{\partial y}=\frac{-\partial C_{s g} U_{G}}{\partial x}
$$

where $U_{s}$ and $U_{g}$ are the superficial velocities of the solid and gas respectively, $C_{s s}$ and $\bar{C}_{s g}$ are the concentrations of sulfur in the solid and the gas respectively, $y$ is the vertical position, and $x$ is the horizontal position.

The right hand side of this equation is equal to the sulfur transport from the gas to the solid. Using this notation and assuming that the superficial velocity of the solid is not a function of $y$, the equation becomes

$$
U_{s} \frac{\partial C_{s s}}{\partial y}=g_{s}
$$


This differential equation has been incorporated into the simulation program to provide an estimate of $\mathrm{C}_{s s}$ as function of bed position.

Empirical Thickness Equation Development. Several assumptions have been made to allow an empirical formula for the precipitate thickness to be found. These assumptions are detailed below.

1. The reaction stops when the concentration of sulfur in the sorbent reaches a specified limit, referred to as $C_{s s t}$.

2. At the critical concentration of precipitate, the precipitate layer covers the entire sirface of the particles with a uniform thickness.

3. It is assumed that the precipitate thickness is a function of the mass of precipitate per unit surface area. It is assumed that the thickness monotonically increases with increasing $C_{s s}$. That is, the thickness will not decrease as a result of ipcreased conversion.

4. The curve will pass through the origin on a plot of the thickness versus $C_{s s}$. That is, the thickness will be zero when there is no precipitate present.

5. The area occupied by the precipitate layer will be less than or equal to the total particle area. This establishes a minimum limit for the thickness at any given $C_{\mathbf{s a}}$.

Use of these assumptions leads to the following qualitative relationship.

$$
\frac{C_{s s t} \epsilon_{s}}{\rho_{p} A} \geq S_{p} \geq \frac{C_{s s} \epsilon_{s}}{\rho_{p} A}
$$

where the lower limit is established by assumption 5 and the upper limit is established by assumption 2. An empirical form which observes these limits as well as the asymptotic behavior described by assumption 4 is

$$
\delta_{p}=C_{s s t}^{(n-1) / n} C_{s s}^{\dot{s} s} \frac{\epsilon_{s}}{\rho_{p} A}
$$

where $\mathrm{n}$ is an adjustable parameter. Once the thickness is known, the area covered by precipitate can be found from 


$$
A_{p}=\frac{C_{s s} \epsilon_{s}}{\rho_{p} \delta_{p}}
$$

The surface area available for mass transfer (not blinded) is related to this using

$$
A_{T \rightarrow p}=A-A_{p}
$$

and finally these equations are combined to give

$$
A_{\operatorname{mip}}=A\left(1-\left(\frac{C_{S s}}{C_{S s t}}\right)^{(n-1) / n}\right)
$$

Experiments have been conducted to determine $C_{s a t}$ by Visneski [1] and Prudich et al. [5]. To be applicable to particles of differing sizes a further assupption must be made. The logical choice is to assume that the precipitate thickness at the critical sulfur concentration will be independent of particle size. This implies that

$$
C_{s s t}=\frac{\alpha}{S_{p} D_{p}}
$$

where $\alpha$ is the primary parameter to be resolved from experiments.

\begin{tabular}{|c|c|c|c|c|c|}
\hline Ref & Limestone & $\begin{array}{l}\text { Maximum } \\
\text { Concentr }\end{array}$ & tion & $\begin{array}{l}\text { Particle } \\
\text { Diameter } \\
\text { (ft) }\end{array}$ & $\alpha$ \\
\hline $\begin{array}{l}{[5]} \\
{[5]} \\
{[5]} \\
{[1]} \\
{[1]}\end{array}$ & $\begin{array}{l}\text { Maxville } \\
\text { Mississippi } \\
\text { Vanport } \\
\text { Maxville } \\
\text { Vanport }\end{array}$ & $\begin{array}{l}6.26 \cdot 10^{-2} \\
5.74 \cdot 10^{-2} \\
4.53 \cdot 10^{-2} \\
1.64 \cdot 10^{-4} \\
5.27 \cdot 10^{-5}\end{array}$ & 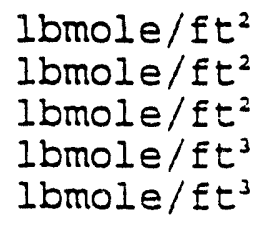 & $\begin{array}{l}2.10 \cdot 10^{-4} \\
2.10 \cdot 10^{-4} \\
2.10 \cdot 10^{-4} \\
7.77 \cdot 10^{-4} \\
9.57 \cdot 10^{-4}\end{array}$ & $\begin{array}{l}6.57 \cdot 10^{-6} \\
6.03 \cdot 10^{-6} \\
4.76 \cdot 10^{-6} \\
9.83 \cdot 10^{-4} \\
3.16 \cdot 10^{-4}\end{array}$ \\
\hline
\end{tabular}
Experimental results are given in Table 3 . Note that concentrations are reported per unit surface area in reference [5] and per unit particle volume in reference [1]

The wide variation in values of $\alpha$ cannot be easily explained. There is an apparent correlation with particle size which suggests that a higher value should be used when modeling desulfurization with granular sorbent. Furthermore, the use of the smaller values found in Table 3 results in simulation predictions which are in strong disagreement with pilot scale 
experimental results [6]. A value for $\alpha$ of $9.83 \cdot 10^{-4}$ has been used in the simulation results.

Prudich et al. [5] have also determined values for $n$ experimentally. They report a value of 1.50 for Maxville limestone, 1.55 for Mississippi limestone, and 2.61 for Vanport limestone. An average value of 1.89 is used here.

\section{TASR I-C: REGENERATION/RECYCLE MODEL}

The final addition to the simulation program is a model describing the operation of the sorbent recovery step and associated cost equations. This step is costed as a vibrating screen. Pilot scale operating experience [6] indicates that the precipitate layer on the sorbent particles can easily be removed by mechanical agitation forming fine particles which can be separated from the larger unreacted sorbent particles by screening. A description of the required material balance equations and costing equations follows.

\section{Mass Balances}

Referring to Figure 2, the following material balance equations can be written

$$
\begin{gathered}
G_{14}=G_{10}-G_{15} \\
G_{15}=\frac{C_{S s 0} G_{6}}{C_{S s I}} \\
G_{1}=G_{6}-G_{: S} \\
G_{10}=G_{6}+20 Q_{g 0} C_{S g 0} F_{S a} \\
C_{S s w}=\frac{F_{S a} Q_{g 0} C_{S g 0} P_{\vdots}}{G_{: i}}
\end{gathered}
$$

Here $G_{:}, G_{5}, G_{10}, G_{14}$, and $G_{: 5}$ are mass flowrates for the sorbent, $C_{s s o}, C_{s s e}, C_{s s w !}$ and $C_{s s r}$ are molar concentrations of sulfur in the sorbent, $Q_{g o}$ is the volumetric feed rate of the gas stream, $C_{s g o}$ is the molar concentration of $\mathrm{SO}_{2}$ in the feed gas and $\mathrm{f}_{\mathrm{sa}}$ is the iractional removal of $\mathrm{SO}_{2}$ in the reactor. These five equations have six unknowns $\left(G_{1}, G_{10}, G_{14}, G_{15}, C_{s s w}\right.$ and $\left.C_{s 9 r}\right)$. $C_{s 80}$ is specified separately as part of the optimization procedure and $G_{5}$ is determined from the specified sorient velocity and reactor 
dimensions.

A performance equation for the operation of the screen is added to this set of equations to provide the sixth equation. The equation is

$$
\left(\frac{C_{\text {Ssw }}}{C_{\text {sswm }}}\right)^{m}=\left(\frac{C_{\text {sgI }}}{C_{\text {ssIm }}}\right)
$$

where $C_{\text {sswm }}$ is the maximum sulfur concentration attainable in the waste, and $\mathrm{m}$ and $\mathrm{C}_{\text {ssm }}$ are adjustable parameters. $C_{\text {ssrm }}$ is taken to have the same value as $C_{\text {sat }}$ (the concentration at which the reaction stops) and $C_{\text {ssum }}$ is determined as follows.

The waste stream is comprised of the $\mathrm{CaSO}_{4}$ formed in the reactor and a fraction of the fresh limestone feed. Since the operation is at steady state, the amount of $\mathrm{CaSO}_{4}$ in the waste is equal to the amount of $\mathrm{SO}_{2}$ captured. The minimum amount of limestone in the waste is dictated by the size of the feed particles and the size of the screen openings. As the outer surface of the limestone particles is reacted to form Caso, this layer is removed and the inner limestone is recycled back to the reactor. This process continues until the particles become small enough to fall through the screen, thus "contaminating" the waste with unreacted limestone. The minimum fraction of the material passing through the screen which is unreacted limestone is equal to the ratio of the volume of a particle just small enough to pass through the screen to the volume of a feed particle or

$$
f=\left(\frac{D_{m}}{D_{p}}\right)^{3}
$$

Since the maximum CaSO, concentration corresponds to the minimum limestone loss, $\mathrm{CsSw}_{\max }$ is found by dividing the moles of $\mathrm{CaSO}_{4}$ produced by the volume of the same $\mathrm{CaSO}_{4}$ produced plus the minimum volume of the unreacted Iimestone lost through the screen.

$$
C_{S s i m}=\frac{Q_{g 0} C_{S g 0} F_{S a}}{\left(\frac{G_{i} f+120 Q_{g 0} C_{S g 0} F_{S a}}{\rho_{i}}\right)}
$$

where $\rho_{\text {: }}$ is the intrinsic mass density of the sorbent. If unreacted limestone is atcrited in the process, the $\mathrm{CaSO}_{4}$ concencration in the waste stream will be lower than $\mathrm{C}_{\text {samm }}$. After setting $C_{\text {saw }}$ equal to $C_{s a w m}$ in the material balances and using a lot of algebra, the expression for $\mathrm{C}_{\mathrm{ssm}}$ can be simplified to 


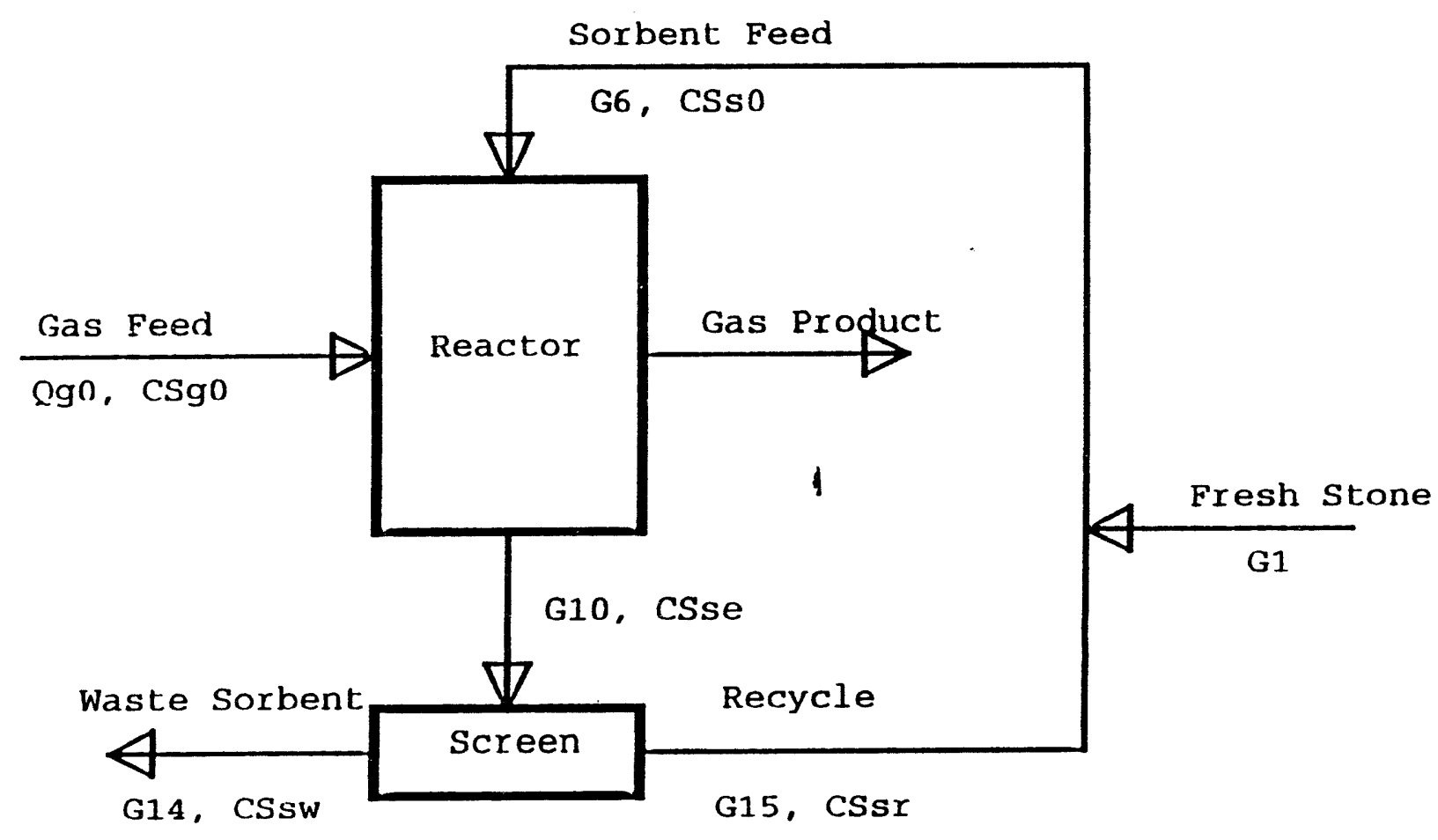

Figure 2. Schematic representation of reactor and sorbent flow showing relevant mass balance variables. 


$$
C_{\text {sswm }}=\frac{p_{1}(1-f)}{20(\sigma-f)}
$$

No information is available at this time to establish an appropriate value for $m$ in the screen performance equation. The value $m=4$ has been used in the simulations because it gives an intuitively reasonable relationship between the concentrations in the two product streams from the screen. Substituting material balance equations into the performance equation gives

$$
C_{s s t}\left(\frac{F_{S a} Q_{g 0} C_{s g 0} P_{1}}{C_{S s w m}\left(G_{10}-\frac{C_{S s 0} G_{6}}{C_{S s I}}\right)}\right)^{m}-C_{S s I}=0
$$

The value of $C_{s a r}$ is found from this implicit equation using an interval halving technique.

\section{Costing}

The capacity of a vibrating screen is assumed to be constant at 0.5 tons $/ \mathrm{hr} / \mathrm{sqft} / \mathrm{mm}$ of mesh size [7]. This means that at a given feed rate, the screen surface area required is inversely proportional to the mesh size. The power requirement for the screen increases with increasing screen area. Therefore, as the mesh size increases, the area and the power requirement of the screen decrease, and the cost of the screen decreases. However, as the screen mesh size increases, a larger portion of unreacted Iimestone will be lost in the waste. The screen size is determined within the simulation algorithm by optimizing the total of the limestone and screen costs using a one variable search and interval halving. The equations used for the purchased cost and power requirement for a vibrating screen are [8]

$$
\begin{aligned}
& \text { Cost }=3200+840 \star \text { Area } \\
& \text { Power }=0.072+0.077 \star \text { Area }
\end{aligned}
$$

where Area is measured in $\mathrm{ft}^{2}$. The search for an optimum screen size is initially bounded both above and below. The minimum screen size is assumed to be 100 mesh. Below about 100 mesh, screening becomes difficult and becomes less attractive as an economical way to effect a separation [7]. The maximum screen size is calculated by setting $C_{\text {sswm }}$ equal to $C_{s s e}$ and using the material balance equations to give a limit for $f$. 


$$
f \leq \frac{\left(1-\frac{100 F_{s a} Q_{g 0} C_{s g 0}}{G_{5}}-\frac{120 C_{s 80}}{\rho_{1}}\right)}{\left(1-\frac{20 C_{s 80}}{\rho_{1}}\right)}
$$

Once this value is known, the corresponding screen size can be calculated from

$$
D_{m}=D_{p} f^{3}
$$

\section{TASR II-A: OPTIMIZATION ALGORITEM}

There are nine independent adjustable design parameters required to specify the operation of the plant. The optimum value for three of these can be determined by inspection. They are the approach to saturation which is set to a practical lower limit of $10^{\circ} \mathrm{F}$, the superficial liquid velocity in the feed which is set to the maximum amount attainable before free draining is induced, and the reactor width (the direction perpendicular to gas and solid flow) which is set to a practical upper limit of 20 ft. The remaining six variables are the inlet solid sulfur concentration $\left(C_{s s o}\right)$, the feed particle diameter $\left(D_{p}\right)$, the superficial gas velocity $\left(U_{g o}\right)$, the sorbent velocity $\left(v_{s}\right)$, the reactor length ( $\mathrm{X}$, the direction parallel to gas flow), and the screen mesh size.

Because of the nature of the calculations, it is logical to break the optimization problem into three parts. Four of the six variables, $C_{s s o}, D_{p}, U_{g o}$, and $v_{s}$, are required to conduct the reactor simulation. This is the outermost optimization search 1000. Since the conditions at any point in the reactor bed depend on only the conditions above and to the left, the performance for several reactor lengths can be determined during one simulation. Optimizing the reactor length is the second level of the optimization search. The third level is optimizing the screen mesh size. Since the simulation conditions and the reactor length determine the operating conditions required for the screen, the mesh size is optimized for each reactor length.

The overall optimization problem proceeds as follows. values for $C_{s s o}, D_{p}, U_{g o}$, and $v_{s}$ are selected. The simulation is started using these values and proceeds from the top of the bed downward one row of large grid elements at a time. This procedure continues until the integrated sulfur removal along the right edge of the first column of large grid elements falls below the target removal efficiency. The reactor height (vertical direction) corresponding to the exact removal efficiency desired is then found by interpolation along the right edge of the first 
large grid element. The corresponding reactor length (horizontal direction) is one large grid element long. The optimal screen size is then found for a reactor of these dimensions and current values of the main search paramecers $C_{s s o}, D_{p}, U_{g o}$, and $V_{s}$. The simulation then continues while the integrated removal efficiency of the second column of large grid elements is monitored. When the removal efficiency again falls below the target value another interpolation and screen optimization are completed for a reactor which is two large grid elements in length. The results from the second column are compared to the results from the first column to determine if the optimum reactor length has been bracketed. This procedure continues until the optimum is bracketed by three points with the cost for the middle point lower than that of either side point.

Once the minimum has been bracketed, an interval reduction routine is employed to refine the estimate. Along the two line segments established by the bounding points, the cost for the plant will vary with reactor length, with reactor height, and, to a much smaller extent, with the concentration of water in the exit gas. Chattopadhyay (4) has shown that the relationship between reactor height and length is nearly linear. Therefore, linear interpolation between the three bounding points can be used to estimate the cost at intermediate points.

The four variables in the outer-most optimization loop are optimized using a library routine titled HSMP32 which is part of the BCSLIB library on the $Y-M P 8$. It is a Quasi-Newton method that employs forward differences to estimate the gradient. It uses a Iine search to help speed convergence to the optimum. The Hessian is estimated and the approximation is updated using two updating formulas, with the initial estimace being the identity matrix. As the hessian approximation moves from the identity matrix to the actual tessian of the function, the method moves from a steepest decent method to Newton's method. For each direction selected a line search is conducted that first brackets the minimum and then fits the functional points to a quadratic and uses the minimum of the quadratic as the next estimate of the minimum of the function. This combination (Quasi-Newton with a line search) was chosen because of the efficient nature of the algorizism $[9,10,11]$.

\section{TASR II-B: PROGRAM RUNS}

\section{Design Basis}

Eight design cases under consideration are differentiated by two levels of sulfur content, 1.5 and 3.5 wt\%, two levels of removal efficiency, 90 and $98 \%$, and two levels of power generation, $100 \mathrm{MW}$ and $500 \mathrm{MW}$. The characteristics of the two coals and the resulting Elue gases are summarized in Tables 4 and 
5 for the 500 MW case. The flue gas characteristics were calculated based upon an assumed $20 \%$ excess air rate, feed air at $80^{\circ} \mathrm{F}$ and $60 \%$ relative humidity, and complete combustion of the coal.

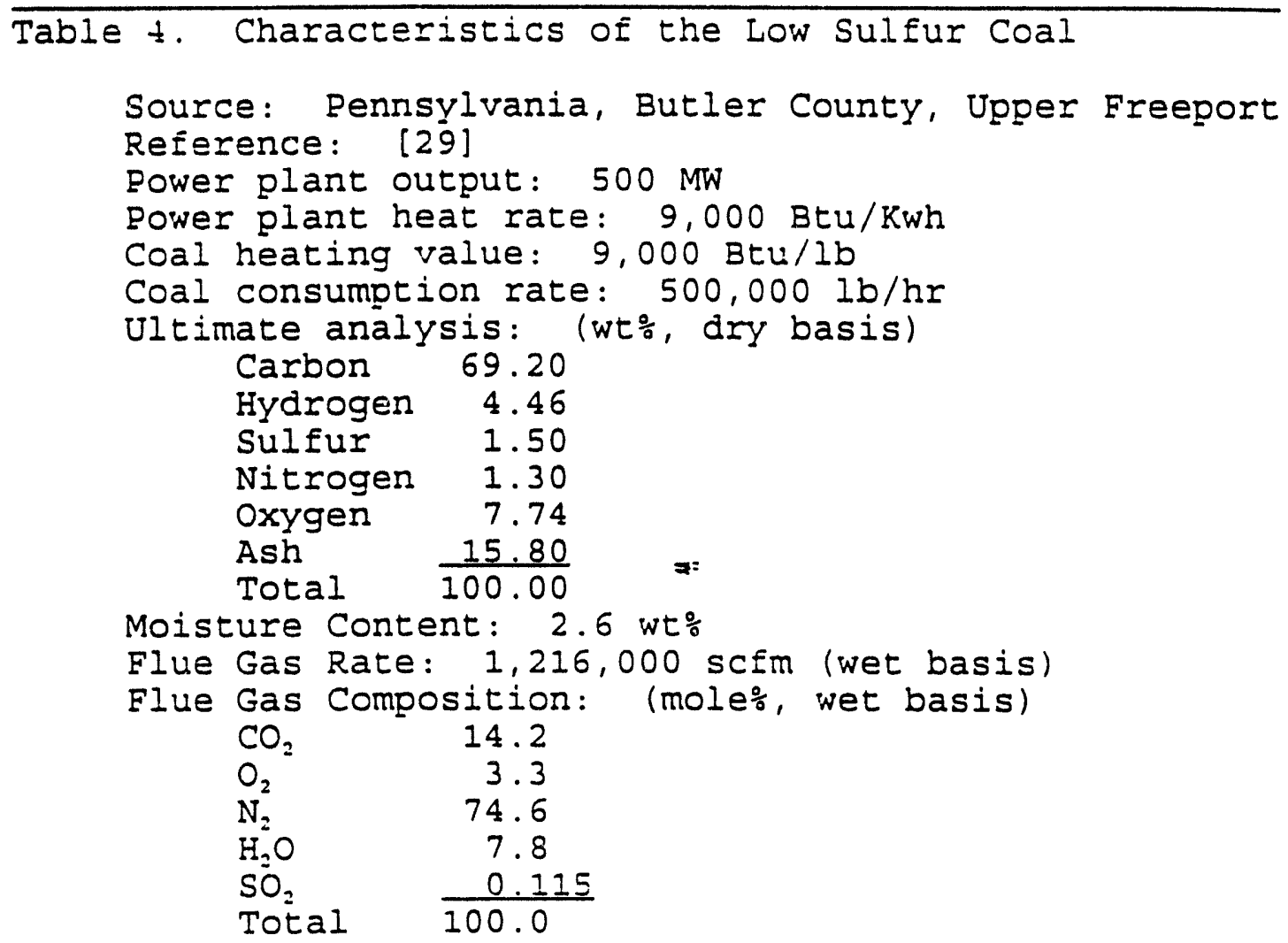


Table 5. Characteristics of the High Sulfur Coal

Source: Ohio, Harrison County, Pittsburgh No. 8 . Reference: [29]

Power plant output: $500 \mathrm{MW}$

Power plant heat rate: $9,000 \mathrm{Btu} / \mathrm{Kwh}$

Coal heating value: $12,000 \mathrm{Btu} / 1 \mathrm{~b}$

Coal consumption rate: $375,000 \mathrm{lb} / \mathrm{hr}$

Ultimate analysis: (wt\%, dry basis)

Carbon 71.30

Hydrogen 5.03

Sulfur $\quad 3.50$

Nitrogen 1.34

Oxygen 9.23

$\begin{array}{ll}\text { Ash } & \frac{9.60}{100.00}\end{array}$

Moisture Content: 2.8 wt\%

Flue Gas Rate: 951,000 scfm (wet basis)

Flue Gas Composition: (mole\%, wet basis)

$\mathrm{CO}_{2} \quad 14.0=$

$\mathrm{O}_{2} \quad 3.3$

$\mathrm{N}_{2} \quad 74.8$

$\mathrm{H}_{2} \mathrm{O} \quad 7.6$

$\mathrm{SO}_{2} \quad \frac{0.2580}{100.00}$

Total 100.0

Evaluation of the Adaptive Grid

The use of the adaptive grid was evaluated using a series of trials with different mesh sizes in the coarse large grid elements. The required fine mesh size of $\Delta x=0.001$ ft and $\Delta y=$ 0.001 ft was determined previously [3]. Runs were completed for the case of the high sulfur coal using the input design paramerers listed in Table 6 and the input numerical parameters isted in Table 7 .

\begin{tabular}{|c|c|}
\hline $\begin{array}{l}\text { Variable } \\
Q_{g 0} \\
E_{S a} \\
X_{S} \\
X_{\text {: }} \\
M_{\text {NO }} \\
T_{\$ 2} \\
T_{\text {as }} \\
T_{10} \\
N_{=} \\
U_{10}\end{array}$ & $\begin{array}{l}\text { Value } \\
31306 \mathrm{ft}^{3} / \mathrm{sec} \\
0.98 \\
0.00115 \\
0.078 \\
29.6 \mathrm{fb} / 1 \mathrm{bmole} \\
760 \circ \mathrm{R} \\
100 \circ \mathrm{R} \\
520 \circ \mathrm{R} \\
20 \mathrm{ft} \\
0 \mathrm{ft} / \mathrm{sec}\end{array}$ \\
\hline
\end{tabular}


Table 7. Results from Evaluation of Adaptive Grid

$\begin{array}{lrrrrr}\text { Parameter } & \text { Run } 1 & \text { Run } 2 & \text { Run } 3 & \text { Run } 4 & \text { Run } 5 \\ \text { NXI } & 12 & 12 & 12 & 12 & 12 \\ \text { NXS } & 250 & 125 & 50 & 25 & 25 \\ \text { NY1 } & 15 & 15 & 15 & 15 & 15 \\ \text { NYS } & 1000 & 500 & 200 & 100 & 100 \\ \text { NS } & 1 & 2 & 5 & 10 & 10 \\ \text { BETA } & 0.001 & 0.001 & 0.001 & 0.001 & 0.0001 \\ \text { SS } & 10 & 5 & 2 & 1 & 1 \\ \text { CPU time (sec) } & 756 & 376 & 260 & \star & \text { * }\end{array}$

* Trial resulted in a run-time error during execution.

In Table $6, \mathrm{X}_{s}$ and $\mathrm{X}_{\mathrm{w}}$ are the mole fractions $\mathrm{SO}_{2}$ and water in the gas phase, $\mathrm{M}_{\alpha_{0}}$ is the average molecular weight of the feed flue gas, $T_{g i}$ is the temperature of the flue gas before humidification, $\mathrm{T}_{\mathrm{as}}$ is the annioach to saturation after humidification, $T_{10}$ is the sorbent feed temperature, $W_{x}$ is the reactor width, and $U_{10}$ is the superficial liquid velocity in the feed. (Note that the specifications for $T_{a s}$ and $U_{10}$ differ from those described in the previous section.)

In Table $7, N X 1$ and $N Y 1$ are the number of large grid elements in the $x$ (horizontal) and $y$ (vertical) directions respectively, NXS and NYS are the number of numerical steps in a coarse large grid element in the $x$ and $y$ directions respectively, NS is the number of points skipped in each direction in the coarse large grid elemencs, BETA is the maximum relative change in $U$, across the top or gas inlet side of a large grid element which can occur and still use the coarse spacing in the grid element, and SS.NS is the number of points skipped along the gas outlet side and bottom of the large grid element when storing the simulation results for the large grid element.

The value of NS.SS has been held constant in Table 7 to eliminate this possible source of numerical inaccuracy from the comparison. As the grid spacing in the coarse elements becomes coarser the total CPU time drops until the numerical algorithm becomes unstable and a run-time error occurs aborting the program. Before this point the results are all very similar indicating that the coarsest stable grid spacing should be used. Parameters indicated under Run 2 were used in subsequent runs to provide a margin of safer

\section{Simulation Results}

Because the optimization algorithm is not yet in full 
operation, optimum results cannot be reported at this time. Instead, representative results for four of the design cases are reported here. Table 8 contains an abbreviaced set of results. Appendix A contains the complete cost analysis for each case and reactor profiles for Run 9 and 11.

\begin{tabular}{|c|c|c|c|c|c|c|}
\hline $\begin{array}{l}\text { Parameter } \\
\mathrm{f}_{\mathrm{sa}} \\
\mathrm{X}_{\mathrm{s}} \text { (ppm) } \\
\mathrm{L}_{\mathrm{x}} \text { (ft) } \\
\mathrm{L}_{\mathrm{f}} \text { (ft) } \\
\mathrm{N}_{\mathrm{g}} \\
\Delta \mathrm{P}\left(\mathrm{in} \mathrm{H}_{2} \mathrm{O}\right) \\
\mathrm{C}_{\mathrm{A}}(\mathrm{MS} / \mathrm{Yr})\end{array}$ & $\begin{array}{c}\text { Run } 6 \\
0.98 \\
2580 . \\
5.0 \\
34.9 \\
35.2 \\
8.3 \\
154 .\end{array}$ & $\begin{array}{c}\text { Run } 7 \\
0.98 \\
2580 . \\
4.0 \\
25.9 \\
46.7 \\
6.7 \\
161 .\end{array}$ & $\begin{array}{c}\text { Run } 8 \\
0.98 \\
2580 . \\
3.0 \\
16.8 \\
70.9 \\
5.0 \\
179 .\end{array}$ & $\begin{array}{c}\text { Run } 9 \\
0.90 \\
2580 . \\
3.0 \\
20.8 \\
57.7 \\
5.0 \\
146 .\end{array}$ & $\begin{array}{c}\text { Run } 10 \\
0.98 \\
1150 . \\
2.5 \\
18.4 \\
82.8 \\
4.2 \\
140 .\end{array}$ & $\begin{array}{c}\text { Run } 11 \\
0.90 \\
1150 . \\
2.5 \\
21.0 \\
72.8 \\
4.2 \\
121 .\end{array}$ \\
\hline
\end{tabular}

In Table $8, L_{x}$ and $L_{y}$ are the reactor dimensions, $N_{9}$ is the number of parallel reactor units that are required, $\Delta \mathrm{P}$ is the pressure drop across the bed, and $C_{A}$ is the annual "system cost" which includes both capital and operating costs.

The results suggest that the optimum bed dimension in the direction of gas flow is more than $5 \mathrm{ft}$. This result does not agree with the expectation that the pressure drop will present a dominating cost for large beds. The annual system cost figures are much higher than expected. A review of the detailed results in Appendix A shows that the cost of the screen is dominant. This is clearly inappropriate and means that the cost figures should be disregarded.

The overall bed dimensions appear to be appropriate and the trends with changing sulfur capture and feed $\mathrm{SO}_{2}$ concentration are correct. The general conclusion that the cost is fairly insensitive to both the sulfur removal and feed $\mathrm{SO}_{2}$ concentration can be supported based only on the fact that the reactor dimensions are fairly insensitive to these changes. 


\section{NOMIMNCLATURE}

The first column represents identification variables used in the computer program code and the second column represents identification variables used in the text.

A a Geometric surface area of the sorbent. (ft2/ft3 of reactor)

AAA -. Intermediate quantity.

AHG $a_{\text {ng }}$ The heat transfer area for transfer between the gas and liquid phases. (ft2/ft3 of reactor)

AMG $a_{a g}$ The mass transfer area in the gas phase boundary layer. (ft2/ft 3 of reactor)

AML $a_{11}$ The mass transfer area in the liquid layer. (ft $2 /$ ft 3 of reactor)

AMP $a_{\text {mp }}$ The mass transfer axea in the precipitate layer. (ft2/ft3 of reactor)

AR(I) A surface area associated with a particular piece of equipment. (ft2)

Ax - Intermediate quantity used in the solution of the differential equations.

BBB -- Intermediate quantity.

BETA $\beta$ The fractional change in superficial liquid velocity over a large grid element (in either the $x$ or $y$ directions). Used to determine the iocation of the drying front.

BFLAG - Flag to determine the if information for the bottom row of the reactor was printed in the subroutine for outputting detailed reactor bed results.

BY - - Intermediate quantity used in the solution of the differential equations.

$C(I) \quad C$ : Installed cost for unit(s) i.

CA $C_{\mathrm{A}}$ Annual system cost for the desulfurization plant. $(\$ / Y r)$

CAL -- Used in determining the optimum reactor width. It is the cost for the plant using the smallest (lower) reactor width in the current width interval. 
CAM -- Used in determining the optimum reactor width. It is the cost for the plant using the median (middle) reactor width in the current width interval.

CAU -- Used in determining the optimum reactor width. It is the cost for the plant using the largest (upper) reactor width in the current width interval.

CCLE $C_{\text {ele }}$ The concentration of $\mathrm{Ca}+$ in the liquid which is in equilibrium with the calcium in the unreacted limestone. The same as the solubility of the limestone. (lbmole/ft 3 of Iiquid)

CNG $C_{\text {Ng }}$ Concentration of non-condensable in the gas phase. (Ibmole/ft 3 of gas)

Co $C_{0}$ Operating cost for the desulfurization plant. $(\$ / h r)$

COLUMN - Variable subscript that refers to the vertical edges of the large grid elements. Starts at 1 - left edge of the reactor, ends at $\mathrm{NX} 1+1$ - right edge of reactor.

CPCS $C_{p c s}$ Heat capacity of sorbent. Includes sulfates, sulfites, and carbonates. (Btu/lbmole calcium ion $/{ }^{\circ} \mathrm{R}$ )

CPG $\quad C_{j g}$ Heat capacity of the gas phase. (Btu/lbmole/oR)

CPNG $C_{p N g}$ Heat capacity of noncondensable. Includes SO2, $\mathrm{CO} 2, \mathrm{~N} 2$, and $\mathrm{O} 2$. (Btu/lbmole $/{ }^{\circ} \mathrm{R}$ )

CPWG $C_{\text {pwg }}$ Heat capacity of water vapor. (Btu/lbmole/oR)

CPWI $C_{p w l}$ Heat capacity of liquid water. (Btu/lbmole/ ${ }^{\circ} \mathrm{R}$ )

CSG $C_{s g}$ The concentration of $S O 2$ in the gas. (1bmole/ft3 of gas)

CSGO $C_{\text {sgo }}$ The concentration of $\mathrm{SO} 2$ in the gas at the reactor inlet. (lbmole/ft 3 of gas)

CSGORI -- The concentration of 502 in the gas at the reactor inlet. (ppm)

CSS $C_{s s}$ The concentration of sulfate or sulfite in the solid. (lbmole/ft 3 of solid)

Csso $C_{s s o}$ The concentration of sulfate or sulfite in the solid at the reactor inlet. (lbmole/ft3 of solid)

CSSE -- The concentration of sulfate or sulfite in the 
solid at the reactor exit. (lbmole/ft3 of solid)

CSSR $C_{s a r}$ The concentration of sulfate or sulfite in the solids in the recycle stream. (lbmole/ft 3 of solid)

CSSRF -- The value of the empirical function of CSSR. Goes to zero at the converged value of CSSR. Used in converging on the proper value for CSSR. (lbmole/ft3 of solid)

CSSRFI - - The value of the empirical function of CSSR when CSSRI is used as the guessed concentration. Goes to zero at the converged value of CSSR. Used in converging on the proper value for CSSR. (lbmole/ft3 of solid)

CSSRFU -- The value of the empirical function of CSSR when CSSRU is used as the guessed concentration. Goes to zero at the converged value of CSSR. Used in converging on the proper value for CSSR. (lbmole/ft3 of solid)

CSSRI -- The lower value of CSSR in the interval bracketing the proper concentration value. (lbmole/ft 3 of solid)

CSSRU -- The upper value of CSSR in the interval bracketing the proper concentration value. (lbmole/ft3 of solid)

CSST $C_{s s t}$ The terminal sulfate or sulfite concentration (the concentration when the reaction is assumed to stop). (lbmoles/ft 3 of solid)

CSSW $C_{\text {ssw }}$ The sulfate or sulfite concentration in the solids in the waste stream. (lbmoles/ft 3 of solid)

CSSWMAX-- The maximum sulfate or sulfite concentration in the solids in the waste stream that can be attained. (Ibmoles/ft 3 of solid)

CWG $C_{\text {ing }}$ The concentration of water in the gas. (1bmole/ft3 of gas)

CWGO $C_{\text {wgo }}$ The concentration of water in the gas at the reactor inlet. (lbmole/ft3 of gas)

CWGE $C_{\text {Nge }}$ The concentration of water in the gas at the reactor exit. (Ibmole/ft3 of gas)

C'NGI $C_{\text {Ng }}$ The concentration of water in the gas at the gas/liquid interface. (Ibmole/ft 3 of gas)

D d power used in empirical relation for the concentration 
of sulfate or sulfite in the solids in the recycle stream.

DCI $D_{C 1}$ Diffusivity of Ca+t in the liquid layer. (ft2/sec)

DELL $\delta_{1}$ Thickness of water layer. ( $\left.f t\right)$

DELP $\delta_{\mathrm{p}}$ Thickness of precipitate layer. (ft)

DELR $\quad \delta_{=}$Thickness of SO3-- (SO4--) diffusion zone. Distance between gas/liquid interface and reaction front. (ft)

DELTAP $\triangle P$ Pressure drop across the bed. (atm)

DEQA A Coefficient of $d P H I / d X$ in the differential equations. Can be a function of the system variables. (Units specific to each equation)

DEQACOL-- Variable name used to store values of DEQA along the vertical edges of the large grid elements.

DEQAN -- New calculation of DEQA from predictor equation.

DEQAROW-- Variable name used to store values of DEQA along the horizontal edges of the large grid elements.

$D E Q B$ B Coefficient of dPHI/dY in the differential equations. Can be a function of the system variables. (Units specific to each equation)

DEQBCOL-- Variable name used to store values of DEQB along the vertical edges of the large grid elements.

DEQBN -- New calculation of $D E Q B$ from predictor equation.

DEQBROW-- Variable name used to store values of DEQB along the horizontal edges of the large grid elements.

DEQE E Value of non-homogenous part in the differential equations. Can be a function of the system variables. (Units specific to each equation)

DEQECCL-- Variable name used to store values of DEQE along the vertical edges of the large grid elements.

DEQEN -- New calculation of DEQE from corrector equation.

DEQEROW-- Variable name used to store values of DEQE along the horizontal edges of the large grid elements.

DP $\quad D_{g}$ Sorbent particle diameter. (ft) 
DPHIi $\Delta \varphi$ : Intermediate quantity used in predictor equation for solving the differential equations (slope evaluated at the base point). i refers to the seven dependent variables.

$\Delta \varphi_{2}$ Intermediate quantity used in the corrector equation for solving the differential equations (slope evaluated at the new point).

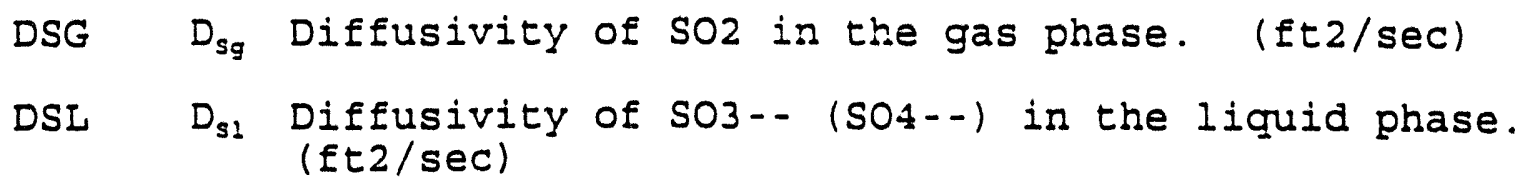

DWG $D_{\text {ivg }}$ Diffusivity of water in the gas phase. (ft2/sec)

DX $\Delta \mathrm{x}$ Numerical step size in the $\mathrm{X}$-direction. (ft)

DY $\quad \Delta y$ Numerical step size in the $Y$-direction. (ft)

E e Exponent in empirical equation that predicts the blinding effect on the sorbent. (dimensionless)

EL -- Element number on a diagonal of grid points.

ELH - - Highest element number on a specific diagonal.

ELL - L Lowest element number on a specific diagonal.

EPSG $\epsilon_{g}$ Fraction of bed occupied by gas. (dimensionless)

EPSGO $\epsilon_{\text {go }}$ Fraction of bed occupied by gas at the reactor inlet. (dimensionless)

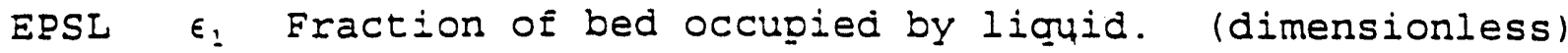

EPSLS $\epsilon_{\text {:s }}$ Maximum fraction of bed occupied by liquid when the liquid is not flowing reiative to sorbent (static liquid volume fraction). (dimensionless)

EPSS $\epsilon$, Fraction of bed occupied by solid. (dimensionless)

Ex -- Intermediate quantity used in solving the differential equations.

EY -- Intermediate quantity used in solving the differential equations.

F - Dummy variable used to return the total system cost. (Used with the optimization routine).

FE(I) $\quad \xi_{\mathrm{s}}$ : Inflation escalator for process unit $i$. 
(dimensionless)

FI(I) $F_{: i}$ Installed cost factor for process unit $i$. (dimensionless)

FINES -- The flow rate of sorbent fines through the screen. $(1 \mathrm{~b} / \mathrm{sec})$

FNG $f_{\text {Ng }}$ Flux of noncondensables in the gas phase in the direction of gas flow. Includes $\mathrm{SO} 2, \mathrm{CO} 2, \mathrm{~N} 2$, and 02. (lbmole/sec/ft2 of reactor)

FP $\quad F_{p}$ Packing factor of the reactor bed. (dimensionless)

FRINT -- Interpolation factor to interpolate between stored points.

FS $f_{s}$ Fraction of the sulfur removed from the flue gas at a given height in the reactor bed. (dimensionless)

FSA $f_{s a}$ Average sulfur remoyal for the reactor bed. (dimensionless)

FSAT $f_{\text {sat }}$ Target average sulfur removal for the bed. (dimensionless)

FWGO $f_{\text {wgo }}$ Flux of water in the gas phase in the direction of gas flow at the gas inlet. (lbmole/sec/ft 2 of reactor)

FWGSTR - The amount of water added through the humidifier. (Ibmols/sec)

$G(I) \quad G$ : Mass flowrate through process unit $i$. $(1 \mathrm{~b} / \mathrm{sec})$

GC ge Conversion factor. ( 32 ftlem/lof/sec2)

GG $g_{g}$ Rate of heat transfer from the gas phase to the liquid phase. (Btu/sec/ft3 of reactor)

GS

$g_{3}$ Rate of transport of sulfur (dioxide) from the gas phase to the solid phase. (1bmole/sec/ft3 of reactor)

GSG - Flux of sulfur in the vapor. (lbmols/sec/ft2 of reactor)

GSGO - Flux of sulfur in the vapor at the reactor inlet. (lbmols/sec/ft2 of reactor)

GN G. Rate of transport of water from the gas phase to 
the liquid phase. (Ibmole/sec/ft3 of reactor)

$H(I) \quad H:$ Height of process unit $i$. (ft)

HDEI - Enthalpy difference between liquid water at the liquid temperature and water rapor at the gas temperature.
(Btu/lbmole)

HG $h_{g}$ Overall heat transfer coefficient between the gas and liquid phases. (Btuisec/ft2/०R)

HS $H_{s}$ Henry's law constant for SO2. Based on

concentration of $\mathrm{SO}--(\mathrm{SO} 4--)$ in liquid phase.

Evaluated at sorbent temperature. (atmft3/lbmole)

I - - Subscript referring to iteration number or variable

ICNT -- Count for number of times a loop executes.

ID -- Diagonal number. Ranges from IDL to IDH.

IDI - Lower limit for diagonal number.

IDH - Upper limit for diagonal number.

IFLAG - Flag to determine if detailed data for the bed should
be printed.

INDEX - - Subscript for vaiables that store information along the edges of the large grid elements. Since not all points are stored, this index relates the element in the array to the location of the point.

INDEX1 - Dummy variable that stores a frequencly used array
subscript.

INDEX2 - Dummy variable that stores a frequently used array
subscript.

INDEXXH-- Upper limit for INDEX for variables that store data in
the X direction.

INDEXXL-- Lower limit for INDEX for variables that store data in
the $X$ direction.

INDEXYH-- Upper limit for INDEX for variables that store data in
the Y direction.

INDEXYL-- Lower limit for INDEX Ecr variables that store data in
the Y direction. 

IRG -. Integer value that indicates the reaction regime
(position of the reaction front).

IRGCOL - Stores IRG data along the vertical edges of the large grid elements.

IRGROW - Stores IRG data along the horizontal edges of the large grid elements.

Is -. The current stride rate, or number of numerical steps being used per iteration. (Measured as the number of numerical step sizesl

IV -- Integer that refers to variable number (range 1-7).

IX -. The point number in the $x$ direction (starting a 1 for the left edge of the reactor).

IX1 - The large grid element number (starting a 1 for the left edge of the reactor).

IXH -. The maximum value for IX in a given large grid element.

IXI -. The minimum value for IX in a given large grid element.

IY -. The point number in the $Y$ direction (starting a 1 for the top edge of the reactor).

IXI - The large grid element number (starting a 1 for the top edge of the reactor).

IY2 -- The point number within a large grid element istarting at 1 for the top of the large grid element).

IXH - - The maximum value for IY in a given large grid element.

IXI -- The minimum value for IY in a given large grid element.

IYMAX - - The point number (IY) that corresponds to the row of the reactor where the calculations stopped (bottom of the reactor was reached or FSA $<=F S A T$ ).

J - - Dummy variable.

$k$ Empirical constant used in dry capture equation. (dimensioniess)

JG $J_{z}$ Factor for heat or mass transfer for gas phase. 
(dimensionless)

KMC $k_{x c}$ The pseudo mass transfer coefficient for Ca+t in the dissolution zone. Based on liquid phase concentrations. (ft/sec)

KMS $k_{n s}$ The mass transfer coefficient for $\mathrm{sO2}$ in flue gas for transport of $\mathrm{SO} 2$ to the surface of the water layer. Based on gas phase concentrations. ( $f t / \mathrm{sec})$

KMW $k_{\text {sw }}$ The mass transfer coefficient for water in flue gas for transport of wacer to or from the surface of the water layer. Based on gas phase concentrations. (ft/sec)

KTG $k_{i g}$ Thermal conductivity of the gas phase. (Btu/sec/ft/ ${ }^{\circ} \mathrm{R}$ )

$I(I) \quad L_{i}$ Length of process unit $i$. (ft)

LAM $\lambda$ Latent heat of vaporization of water. Evaluated at Tl. (Btu/lbmole)

IX $L_{x}$ Length of bed in $x$ direction. (ft)

Iy $\quad I_{i}$ Length of bed in $y$ direction. (ft)

$M(I) \quad M_{i}$ Mass of sorbent in process unit $i$ or mass of process unit $i$. (1b)

Mo -. The molecular weight of the gas at the reactor inlet. (1b/lbmole)

ME - The molecular weight of the gas at the reactor exit. (1b/lbmole)

MESF - The screen opening size. (ft)

MESHI - - The lower limit for MESH. The lower bracket of the optimum values for MESH. (feet)

MESHM -- The median value for MES: in the bracket of the optimum values for MES:i. (ft)

MESHL - - The upper limit for MESH. The upper bracket of the optimum. values for MESH. (Et)

MG $\because \exists$ Average molecular iveight in the gas phase. (lb/lbmole)

MN - Molecular weight of the non-condensables in the gas ( $1 \mathrm{~b} / 1 \mathrm{bmole}$ ) 
MUG $\mu_{g}$ Viscosity of the gas phase. (1bmole/ft/sec)

MUGO $\mu_{g 0}$ Viscosity of the gas phase at the reactor inlet. (lbmole/ft/sec)

MUT, $\quad \mu_{1}$ Viscosity of the liquid phase. (1bmole/ft/sec)

$N$ (I) N. Number of parallel units of type $i$. (dimensionless)

NCOLS -- The number of columns (vertical edges on the large grid elements).

NELS -- The total number of elements on a diagonal.

NF N: Number of calls to subroutine DEQTERMS.

NGA $\mathrm{N}_{\mathrm{sa}}$ Galileo Number. (dimensionless)

NPRG $N_{\text {prg }}$ Prandtl number for the gas phase. (dimensionless)

NREG $N_{R e g}$ Reynolds number for the gas phase. (dimensionless)

NREL $N_{R e l}$ Reynolds number for the liquid phase. (dimensionless)

NROWS -- The number of rows (horizontal edges on the large grid elements).

NS -- The stride to be used when not near the drying front (measured in number of numerical steps).

NSCS $\mathrm{N}_{\mathrm{scs}}$ Schmidt number for sulfur dioxide in the gas phase. (dimensionless)

NSCW $\mathrm{N}_{\mathrm{scw}}$ Schmidt number for water in the gas phase. (dimensionless)

NV -- The number of optimization variables (used with the optimization routine).

NX - The width of the reactor measured in number of points (number of numerical steps in the $x$ direction).

NX1 - The width of the reactor measured in the number of large grid elements in the $x$ direction.

NX2 - The width of a large grid elements measured in numerical steps in the $x$ direction.

NXOUT - The number of points in the $x$ direction skipped between outputs for the detailed bed conditions. 
NXPNTS - - The number of points along the horizontal edges of
the large grid elements to be stored (dimension of
the "Row" arrays).

NXS -. The number of strides required to span the width of a large grid element (in the $x$ direction).

NY -- The height of the reactor measured in number of points (number of numerical steps in the $y$ direction).

NY1 -- The height of the reactor measured in the number of large grid elements in the $y$ direction.

NY2 - The height of a large grid elements measured in numerical steps in the $y$ direction.

NYOUT -- The number of points in the $y$ direction skipped between outputs for the detailed bed conditions.

NYPNTS -- The number of points along the vertical edges of the large grid elements to be stored (dimension of the "COL" arrays).

NYS - The number of strides required to span the height of a large grid element (in the $y$ direction).

OFIAG -- Flag to determine if detailed cost information should be printed.

$P(I) \quad P$ : Power consumption for unit i. (KW)

$\operatorname{PHI}(I) \varphi_{i}$ Represent the system variables $(i=1-7)$

PHICOL -- Variable name for array used to store PHI values along the vertical edges of the large grid elements.

PHIN -- New value for phi generated from the corrector equation.

PHIRON -- Variable name for array used to store PHI values along the horizontal edges of the large grid elements.

PHIX - Intermediate quantity used in the solution of the differential equations.

PHIY -- Intermediate quantity used in the solution of the differential equations.

PW $\quad P_{\text {N }}$ Vapor pressure of warer evaluated at sorbent temperature. (atm)

pws -- The vapor pressure of water evaluated at the gas 
temperature (saturation vapor pressure).

Q - Wegstien search paramerer.

$Q A Q_{A}$ The amount of compressed air required for humidification system. (1bmole/sec)

QGO Qgo Total volumetric flowrate of flue gas in all parallel units at the gas inlet. (ft3/sec)

QGE -- Total volumetric flowrate of gas our of all reactor units. (ft $3 / \mathrm{sec})$

QGES -- Total standard volumetric flowrate of gas our of all reactor units. (std $\mathrm{ft} 3 / \mathrm{sec})$

QW Qw The amount of water required for humidification system. (lbmole/sec)

$R \quad R$ Ideal gas constant. (ft $3 \mathrm{~atm} / \mathrm{lbmole} /{ }^{\circ} \mathrm{R}$ )

RFLAG - - Indicates if information for the right edge of the reactor was printed.

RHOB $\rho_{b}$ The bulk density of the sorbent (1b/ft3 of reactor)

RHOG $\rho_{g}$ The density of the gas phase. (Ibmole/ft3 of gas)

RHOGO $\rho_{g o}$ The density of the gas phase at the reactor inlet. (lbmole/ft 3 of gas)

RHOI $\rho_{2}$ The intrinsic density of the sorbent. (lbs/ft3 of sorbent)

RHOL $\rho_{1}$ The density of the liquid phase. Same as CWl. (lbmole/ft3 of liquic)

RHOP $\rho_{p}$ The density of the precipitate layer. (lbmole calcium/ft3 of precipitate)

RHOS $\rho_{\text {s }}$ The density of the solid phase. Same as CCs. (lbmole calcium/ft 3 of solid)

SP $\quad S_{3}$ Sphericity of sorbent particle. (dimensionless)

SS -- The number of stride rates skipped between storing points along the edges of the large grid elements.

SUMCNG -- Integral of CiNG over the $\because$ direction.

SUMFS -- Integral of FS over the $\underline{v}$ direction. 
SUMTGE - - Integral of TGE over the $Y$ direction.

TAS - Approach to saturation temperature of the flue gas after being humidified. (OE)

TAU(I) T: Holdup time for unit $i$. (sec)

TG $T_{\Xi}$ Temperature of the gas phase. $\left({ }^{\circ} \mathrm{R}\right)$

TGO $T_{g 0}$ Temperature of the gas pinase at the reactor inlet. $(\circ \mathrm{R})$

TGE Tge Temperature of the gas phase at the reactor exit. $\left({ }^{\circ} R\right)$

TGI $T_{g_{2}}$ Temperature of the gas phase prior to being humidified. ( $\left.{ }^{\circ} \mathrm{R}\right)$

TL $T_{1}$ Temperature of the liquid phase. ( $\left.{ }^{\circ} \mathrm{R}\right)$

TLO $T_{10}$ Temperature of the liquid phase at the reactor inlet. $\left({ }^{\circ} \mathrm{R}\right)$

UG $U_{\Xi}$ Superficial velocity of the gas phase. (ft3 gas/ft2 reactor/sec)

UGO $U_{g 0}$ Superficial velocity of the gas phase at the reactor inlet. (ft3 gas/ft2 reactor/sec)

UL U, Superficial velocity of the liquid phase. (ft3 liquid/Et2 reactor/sec)

ULO U:o Superficial velocity of the liquid phase at the reactor inlet. (ftj liquid/ft 2 reactor/sec)

ULMX -- The maximum superficial liquid velocity attainable before relative flow betiveen the liquid and sorbent begins. (ft3 liquid/ft2 reactor sec)

US $U_{s}$ Superficial velocity of the solid phase. (ft3 gas/Et 2 reactorisec)

$V(I) \quad \ddot{v}_{i}$ Volume of process unit $\vdots$. (Et 3 )

VS $\quad v_{s}$ Velocity of the solid phase. (ft/sec)

WR - - width of reactor unit. (ft)

$x \quad x$ Horizontal direction. The value is zero at the point where the Ilue gas enters the bed. (ft)

XS -. The mole fraction of sulfur dioxide in the flue gas as 
40

supplied from the power plant.

XW -- The mole fraction of water in the flue gas as supplied from the power plant.

XWo -- The mole fraction of water in the flue gas at the reactor inlet.

XWE -- The mole fraction of water in the flue gas at the reactor exit.

$y \quad y$ Vertical direction. The value is zero at the point where the sorbent phase enters the bed. (ft)

YGW -- Mole fraction of water in the gas.

YR $\quad Y_{=}$Relative humidity.

YRI $Y_{z=}$ Relative humidity at the reactor inlet. 


\section{REFERENCES}

1) M.J. Visneski, "Modeling of the Low Temperature Reaction of Sulfur Dioxide and Limestone Using a Three Resistance Film Theory Instantaneous Reaction Model," M.S. Thesis, Ohio University (1991).

2) J. Klingspor, H.T. Karlsson, and I. Bjerle, "A Kinetic study of Dry $\mathrm{SO}_{2}$ Limestone Reaction at Low Temperature," Chem. Eng. Comm. 22, $81(1983)$.

3) K.J. Sampson, M.E. Prudich, S. Chattopadhyay, and S.N. Reddy, "Process Configurations/Modeling" Year One Final Report, Ohio Coal Research Consortium (1992).

4) S. Chattopadhyay, "Modeling and Evaluation of Granular Limestone Dry Scrubbing Process," M.S. Thesis, Ohio University (1992).

5) M.E. Prudich, K.J. Sampson, L. Ben-Said, M. Maldei, "Low Temperature Dry Scrubbing Reaction Kinetics and Mechanisms" Year Three Third Quarterly Report, Ohio Coal Research Consortium (1993).

6) M.E. Prudich, K.W. Appell, M.J. Visneski, J.D. McKenna, D.A. Furlong, J.C. Mycock, J.F. Szaley, J. Wright, "Small Pilot plant Demonstration of ETS' Limestone Emission Control System" Final Report, Ohio Coal Development Office (1988).

7) i.1. MCCabe and J.C. Smith, Unit Operations of Chemical Encineering, 2nd ed., McGraw-Hill (1967).

8) M.S. Deters and K.D. Timmerhaus, plant Design and Economics for Chemical Enaineers, 4 th ed., McGraw-Hill (1991).

9) D.M. Himmelblau, Apolied Noninear programming, McGraw-Hill $(1972)$.

10) G.V. Reklaitis, A. Ravindran, and K.M. Ragsdell, Engineering optimization, Wiley-Interscience (1983).

II) W.D. Seider, J.D. Seader, and L.I. Biegler, "Mathematical Modeling and Optimization," AIChE Continuing Education Course Notes, American Institure of Chemical Engineers (1988). 
APPENDIX - SIMULATION RESULTS

Run 6

MOVING BED REACTOR SIMULATION

Plant Cost Information

Design Variables $\times 1000$

Solid Sulfur Conc. Particle Diameter Gas Velocity Solid Velocity $\begin{array}{llll}0.01000 & 10.00000 & 1500.0000 & 6.00000\end{array}$

Reactor length (X-direction). ( $f t)$
Reactor depth (Y-direction). (ft)
Reactor width (Z-direction) (ft)

Percentage of $\mathrm{SO} 2$ removed.

Number of reactor units.

SO2 gas conc. at reactor inlet.

Initial solid sulfur conr.

Relative humidity at inlt.

Inlet gas temperature. ( $k$ )

Inlet solid/liquid temperature. (R)

Iniet superficial gas velocity. (ft/s)

Inlet superficial Iiquid velocity. (ft/s)

Sorbent superficial velocity. (ft/s)

Sorbent particle diameter. (ft)

Input flue gas flow rate. (acf/sec)

press. drop. (inch. H2O column)

Mesi size used in screen (mm)

Limestone mass flow rates:

Flowrate thru Feed Hopper \# 1. (1b/sec)

Flowrate thru Elevator \#4. ( $\#$. $/ \mathrm{sec}$ )

Flowrate thru Storage Tank \#6. (1b/sec)

Flowrate thru Belt Conveyor $\# 8$. ( $1 \mathrm{~b} / \mathrm{sec}$ )

Flowrate thru each Reactor \# 9 .

$(1 \mathrm{~b} / \mathrm{sec})$

Flowrate thru Belt Conveyor $\# 10$.

Flowrate thru Belt Conveyor $\# 14$.

Flowrate thru Belt Conveyor \# 15 .

$(1 \mathrm{~b} / \mathrm{sec})$

$(1 \mathrm{~b} / \mathrm{sec})$

( $1 \mathrm{~b} / \mathrm{sec})$

5.00 by 0.00100
34.94 by 0.00100
20.00

98.00

35.19

2482 .

0.0000100

10.75

671.85

520.00

1.5000

0.0000000

0.00326

0.01000

34781.46

8.313

2.18331

3429.77

5027.53

1940.74

1940.74

55.16

1944.19

352.93

1597.76

20000.00

6986650.95

1166511.08

Mass of sorbent:

Sorbent in Feed Hopper $\# 1$. (1b)

Sorbent in Storage Tank \#6. (Ib)

Sorient in Holding Bin $\neq 11$. 
Power Requirements:

Screw Feeder \# 2. (KW)

Belt Conveyor \# 3 .

(KW)

Bucket Elevator \#4. (KN)
Belt Conveyor \#5. (KN)

93.4

79.0

Screw Feeder \# 7. (KW)

Belt Conveyor \# 8 . (KW)

Belt Conveyor \# 10. (KW)

Screw Feeder \# 12. (KW)

Belt Conveyor \# 14. (KW)

Belt Conveyor \# 15. (KW)

I.D. Fan \# 16. (KW)

Humidification System $\# 17$. (KW)

1350.2

115.8

68.1

65.9

66.1

60.2

8.1

25.3

433.7

78.7

Total power requirement. (KWh)

2935.4

Total Cost of Power. (K\$/Year)

Total Cost of Water. (K\$/Year)

540.0

173.1

Total Cost of Sorbent. (K\$/Year)

Total Operating Cost. (K\$/Year)

Cost of Feed Hopper \#1. (KS)

Cost of Screw Feeder \# 2. (K\$)

Cost of Belt Conveyor \# 3 . (KS)

Cost of Bucket Elevator \#4. (KS)

Cost of Belt Conveyor \# 5 . (KS)

Cost of Storage Tank \# 6. (KS)

Cost of Screw Feeder $\# 7$. (KS)

$\begin{array}{lll}\text { Cost of Belt Conveyor } \# 8 \text {. } & \text { (KS) } \\ \text { Cost of Reactor Units } \# 9 . & \text { (KS) }\end{array}$

Cost of Belt Conveyor \# 10 . (KS)

Cost of Holding Bin \#11. (K\$)

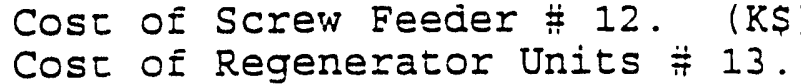

(KS)

Cost of Belt Conveyor \# 14. (KS)

Cost of Belt Conveyor \# 15. (KS)

5712.8

Cost of I.D. Fan \#16. (KS)

Cose of Humidification system \# $\# 17$.

(K\$)

76425.8

Total Fixed Cost. (K\$)

27.4

4.6

112.7

4090.1

112.7

1650.1

20.9

190.3

8247.1

190.3

471.4

13.1

440458.1

112.7

61.6

327.5

250.9

456341.5

SYSTEM COST. (KS/Year)

154003.9 
RQR 7

MOVING BED REACTOR SIMULATION

Plant Cost Information

Design Variables $\times 1000$ $\begin{array}{rccc}\text { Solid Sulfur Conc. Particle Diameter } & \text { Gas Velocity } & \text { Solid Velocit } \because \\ 0.01000 & 10.00000 & 1500.0000 & 6.00000\end{array}$

Reactor length (X-direction).

Reactor depth ( $Y$-direction).

Reactor width (z-direction).

$(f t)$

4.00 by 0.00100

25.93 by 0.00100

Percentage of $\mathrm{SO} 2$ removed.

$\left(\frac{\circ}{6}\right)$

20.00

Number of reactor units.

98.00

SO2 gas conc. at reactor inlet. (ppm)

Initial solid sulfur conc. (lbmols/cuft)

Relative humidity at inlet.

(웅)

Inlet gas temperature. (R)

Inlet solid/liquid temperature. (R)

Inlet superficial gas velocity. (ft/s)

Inlet superficial Iiquid velocity. (ft/s)

Sorbent superficial velocity.

Sorbent particle diameter. (ft)

( $f t / s)$

46.71

Input flue gas flow rate. (acf/sec)

Press. drop. (inch. H2O column)

Mesh size used in screen (mm)

2482 .

0.0000100

10.75

671.85

520.00

1.5000

0.0000000

0.00326

0.01000

34781.46

6.651

Limestone mass Elow rates:

Flowrate thru Feed Hopper $\neq 1$. (1b/sec)

Flowrate thru Elevator $\# 4$. (Ib/sec)

Flowrate thru storage Tank \#6. (Ib/sec)

Flowrate thru Belt Conveyor $\# 8$. ( $1 \mathrm{~b} / \mathrm{sec})$

Flowrate thru each Reactor $\# 9$. (Ib/sec)

Flowrate thru Belt Conveyor $\# 10$. (Ib/sec)

Flowrate thru Belt Conveyor \#14. (1b/sec)

Flowrate thru Belt Conveyor \#15. (1b/sec)

2.20628

Mass of sorbent:

Sorbent in Feed Hopper $\# 1$. (1b)

Sorbent in Storage Tank $\# 6$. (Ib)

Sorbent in Holding Bin $=11$. (1b)

3495.43

5207.19

2061.30

2061.30

44.13

2064.75

361.13

1711.75

Power Requirements: 
Screw Feeder \#2. (KN)

Belt Conveyor \#3. (KW)

Bucket Elevacor \#4. (KW)

Belt Conveyor \# 5 . (KW)

Screw Feeder \# 7 . (KW)

Belt Conveyor \# 8. (KW)

Belt Conveyor \# 10 . (KN)

Screw Feeder \#12. (KN)

Belt Conveyor \# 14 . (KW)

Belt Conveyor \# 15. (KW)

I.D. Fan \# 16 . (KW)

Humidification System \# 17 . (KN)

Total power requirement. (KWh)

Total cost of Power. (KS/Year)

Total Cost. of Water. (K\$/Year)

Total Cost of Sorbent. (KS/Year)

Total operating Cost. (KS/Year)

Cost of Feed Hopper \# 1 . ( $\overline{\mathrm{KS}}$ )

Cost of Screw Feeder $\# 2$. (K\$)

Cost of Belt Conveyor \#3. (K\$)

Cost of Bucket Elevator \# 4 .

Cost of Belt Conveyor $\# 5$. (KS)

Cost of Storage Tank \#6. (KS)

Cost of Screw Feeder \# 7 . (KS)

Cost of Belt Conveyor $\# 8$. (KS)

Cost of Reactor Units \# 9 . (KS)

Cost of Belt Conveyor $=10$. (KS)

Cost of Holding Bin \#11. (KS)

Cost of Screw Feeder \#12. (K\$)

Cost of Regenerator Units \#13. (K\$)

Cost of Belt Conveyor $\# 14$. (KS)

Cost of Belt Conveyor $=15$. (KS)

Cost of I.D. Fan \# 16. (K\$)

Cost of Humidification System $\equiv 17$.

Total Fixed Cost. (K\$)

$(K \$)$

SYSTEM COST. (KS/Year)
95.1

80.5

1398.4

120.0

72.7

73.3

73.4

64.1

8.3

27.1

347.0

78.7

2954.6

543.5

173.1

77162.4

77879.0

27.4

4.6

112.7

4236.3

112.7

1721.2

21.2

201.5

8657.3

201.5

491.6

13.3

474993.4

112.7

61.6

313.0

250.9

491532.9

161439.6 
Rus 8

MOVING BED REACTOR SIMULATION

Plant Cost Information

Design Variables $\times 1000$

Solid Sulfur Conc. Particle Diamerer Gas Velocity Solid Velocity $\begin{array}{rrrr}0.01000 & 10.00000 & 1500.0000 & 6.00000\end{array}$

Reactor length (X-direction). ( $f t)$
Reactor depth (Y-direction). (ft)

Reactor width (z-direction). (ft)

Percentage of $\mathrm{SO} 2$ removed.

Number of reactor units.

SO2 gas conc. at reactor inlet. (ppm)

Initial solid sulfur conc. (lbmols/cuft)

Relative humidity at inlet.

Inlet gas temperature.

$(R)$

Inlet solid/liquid temperature. (R)

Inlet superficial gas velocity. (ft/s)

Inlet superficial liquid velocity. (ft/s)

Sorbent superficial velocity. (ft/s)

Sorbent particle diameter. (ft)

Input flue gas flow rate. (acf/sec)

Press. drop. (inch. H2O column)

Mesh size used in screen (mm)

Limestone mass flow rates:

Flowrace thru Feed Hopper \# 1 .

Flowrate thru Elevacor \# 4 .

Flowrate thru storage Tank \#6

Flowrate thru Belt Conveyor \# 8 .

Flowrate thru each Reactor \# 9 .

Flowrate thru Belt Conveyor $\# 10$.

Flowrate thru Belt Conveyor \#14.

Flowrate thru Belt Conveyor \#15.

Mass of sorbent:

Sorbent in Feed Hopper \# 1 . (1b)

Sorbent in Storage Tank $\# 6$. (1b)

Sorbent in Holding Bin \# 11 .

3.00 by 0.00100
16.84 by 0.00100
20.00

98.00

70.86

2482 .

0.0000100

10.75

671.85

520.00

1.5000

0.0000000

0.00326

0.01000

34781.46

4.988

2. 25788

3654.63

5634.13

2344.97

2344.97

33.09

2348.42

380.50

1979.50

$(1 \approx$ 'sec

( $1 \mathrm{~b} / \mathrm{sec}$ )

20000.00

8441883.89

1409049.90

Power Requirements:

Screin Feeder \#2. (KW)

99.5 
Belt Conveyor \# 3. (KW)

Bucket Elevator \# 4. (KW)

84.2

Belt Conveyor \#5. (KW)

1513.1

129.8

83.6

92.0

Belt Conveyor \# 8 . (KW)

92.2

Belt Conveyor \#10. (KW)

73.5

Screw Feeder \#12. (KW)

8.8

Belt Conveyor \#14. (RW)

Belt Conveyor \# 15. (KW)

I.D. Fan \# 16. (KW)

31.4

260.2

78.7

Humidification System \# 17. (KW)

3120.4

Total power requirement. (KWh)

574.0

173.1

Total Cost of Water. (KS/Year)

Total Cost of Sorbent. (K\$/Year)

80676.7

Total Operating Cost. (K\$/Year)

81423.8

Cost of Feed Hopper \# 1. (KS)

Cost of Screw Feeder \# 2. (K\$)

Cost of Belt Conveyor \#3. (KS)

Cost of Bucket Elevarer \# 4. (K\$)

Cost of Belt Conveyor \#5. (K\$)

Cost of storage Tank \#6. (KS)

Cost of Screw Feeder \# 7 . (KS)

Cost of Belt Conveyor \# 8 . (K\$)

Cost of Reactor Units \# 9. (K\$)

Cost of Belt Conveyor $\# 10$. (K\$)

Cost of Holding Bin \# 11. (K\$)

Cost of Screw Feeder \# 12 . (K\$)

Cost of Regenerator Units \# 13 .

$\begin{array}{lll}\text { Cost of Belt Conveyor } \# 14 . & \text { (KS) } \\ \text { Cost of Belt Conveyor } \# 15 . & \text { (KS) }\end{array}$

(KS)

27.4

4.6

112.7

4583.6

112.7

1883.8

21.9

227.8

9670.6

227.8

538.0

13.8

557647.6

112.7

61.6

294.1

Cost of I.D. Fan \# 16. (KS)

250.9

Total Fixed Cost. (K\$)

575791.5

SYSTEM COST. (K\$/Year)

179308.3 
Run 9

MOVING BED REACTOR SIMULATION

Plant Cost Information

Design Variables $\times 1000$ $\begin{array}{cccc}\text { Solid sulfur Conc. Particle Diameter } & \text { Gas velocity solid velocit } \because \\ 0.01000 & 10.00000 & 1500.0000 & 6.00000\end{array}$

Reactor length (X-direction). (ft)

Reactor depth ( $Y$-direction). (ft)

Reactor width (z-direction). (ft)

Percentage of $\mathrm{SO} 2$ removed.

Number of reactor units. -

(q)
SO2 gas conc. at reactor inlet. (ppm)

Initial Solid sulfur conc. (lbmols/cuft)

Relative humidity at inlet.

Inlet gas temperature. (R)

Inlet solid/liquid temperature. ( $R$ )

Inlet superficial gas velocity. (ft/s)

Inlet superficial liquid velocity.

Soricent superficial velocity. (ft/s)

Sorienc particle diameter. (ft)

Input flue gas flow rate. (act/sec)

Press. drop. (inch. H2O column)

Mesh size used in screen (mm)

Limestone mass flow rates:

Flowrate thru Feed Hopper \#1. (1b/sec)

Flowrate thru Elevator \#4. (1b/sec)

Flcirate thru Storage Tank $\# 6$. (1b/sec)

Flowrate thru Belt Conveyor $\# 8$. ( $1 \mathrm{~b} / \mathrm{sec})$

Flowrate thru each Reactor \#9. (Ib/sec)

Flowrate thru Belt Conveyor $\neq 10$. (1b/sec)

Flowrate thru Belt Conveyor \# 14 .

Flowrate thru Belt Conveyor $\# 15$.

$(1 \mathrm{~b} / \mathrm{sec})$

$(1 \mathrm{~b} / \mathrm{sec})$
3.00 by 0.00100
20.80 by 0.00100
20.00

90.00

57.74

2482 .

0.0000100

10.75

671.85

520.00

1.5000

0.0000000

0.00326

$0: 01000$

34781.46

4.988

2.20069

3198.93

4789.91

1910.88

1910.88

33.09

1914.05

329.69

1590.99

20000.00

6879163.66

1148427.62

Power Requirements:

Screw Feeder \#2. (KW) 
Belt Conveyor \#3. (KW)

Bucket Elevator \#4. (KW)

73.7

1286.4

110.4

Belt Conveyor \#5. (KN)

66.9

Screw Feeder \# 7. (KW)

64.2

Belt Conveyor \#8. (KW)

64.3

Belt Conveyor \# 10. (KW)

59.2

Screw Feeder \# 12. (KW)

7.6

Belt Conveyor \# 14. (KW)

25.2

I.D. Fan \#16. (KW)

(KW)

Humidification system \# 17.

(KN)

260.2

78.7

Total power requirement. (KWh)

2663.3

Total Cost of Power. (KS/Year)

489.9

Total Cost of Water. (KS/Year)

173.1

Total Cost of Sorbent. (KS/Year)

70616.9

Total Operating Cost. (K\$/Year)

71279.9

Cost of Feed Hopper \# 1. (K\$)

Cost of Screw Feeder \# 2. (KS)

Cost of Belt Conveyor \# 3. (KS)

Cost of Bucket Elevator \# 4 .

Cost of Belt Conveyor \#5. (kS)

(KS)

Cost of storage Tank \#6. (KS)

Cost of Screw Feeder \# 7. (K\$)

Cost of Belt Conveyor \# 8. (K\$)

Cost of Reactor Units \# 9. (KS)

Cost of Belt Conveyor \# 10. (KS)

Cost of Holding Bin \# 11. (KS)

Cost of Screw Feeder \# 12 . (K\$)

Cost of Regenerator Units \#13. (KS)

Cost of Belt Conveyor \# 14. (KS)

Cost of Belt Conveyor \# 15. (KS)

Cost of I.D. Fan \# 16. (KS)

Cost of tumidification system $=17$.

(KS)

27.4

4.6

112.7

3896.8

112.7

1632.3

20.8

187.6

8861.5

187.6

466.2

13.0

424981.7

112.7

61.6

296.4

250.9

Total Fixed Cost. (KS)

441226.5

SYSTEM COST. (KS/Year)

146288.4 
Detailed Bed Conditions

\begin{tabular}{|c|c|c|c|c|c|c|c|c|}
\hline $\begin{array}{r}x \\
000\end{array}$ & $\begin{array}{r}Y \\
.000\end{array}$ & $\begin{array}{l}I L * E 6 \\
0.00 \\
0.00 \\
0.00 \\
0.00 \\
0.00 \\
0.00 \\
0.00 \\
0.00 \\
0.00 \\
0.00 \\
0.00 \\
0.00 \\
0.00\end{array}$ & $\begin{array}{r}T L \\
520.000 \\
520.000 \\
520.000 \\
520.000 \\
520.000 \\
520.000 \\
520.000 \\
520.000 \\
520.000 \\
520.000 \\
520.000 \\
520.000 \\
520.000\end{array}$ & $\begin{array}{r}\text { TG } \\
671.850 \\
520.000 \\
520.000 \\
520.000 \\
520.000 \\
520.000 \\
520.000 \\
520.000 \\
520.000 \\
520.000 \\
520.000 \\
520.000 \\
520.000\end{array}$ & $\begin{array}{l}\text { UG } \\
1.5000 \\
1.0488 \\
1.0488 \\
1.0488 \\
1.0488 \\
1.0488 \\
1.0488 \\
1.0488 \\
1.0488 \\
1.0488 \\
1.0488 \\
1.0488 \\
1.0488\end{array}$ & $\begin{array}{l}C S G * E 6 \\
5.0589 \\
5.6950 \\
3.8850 \\
2.0749 \\
0.2649 \\
0.0000 \\
0.0000 \\
0.0000 \\
0.0000 \\
0.0000 \\
0.0000 \\
0.0000 \\
0.0000\end{array}$ & $\begin{array}{l}\text { CSS } \\
0.0000 \\
0.0000 \\
0.0000 \\
0.0000 \\
0.0000 \\
0.0000 \\
0.0000 \\
0.0000 \\
0.0000 \\
0.0000 \\
0.0000 \\
0.0000 \\
0.0000\end{array}$ & $\begin{array}{r}\text { CWG*E6 } \\
217.66 \\
29.51 \\
29.51 \\
29.51\end{array}$ \\
\hline 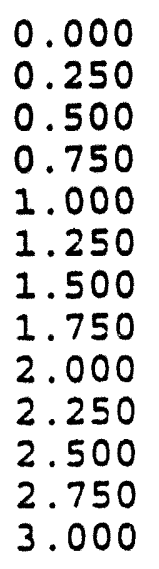 & $\begin{array}{l}1.0 \\
1.0 \\
1.0 \\
1.0 \\
1.0 \\
1.0 \\
1.0 \\
1.0 \\
1.0 \\
1.0 \\
1.0 \\
1.0\end{array}$ & $\begin{array}{l}0.00 \\
9.63 \\
9.55 \\
9.56\end{array}$ & $\begin{array}{l}5 \\
5 \\
5 \\
5 \\
5 \\
5 \\
5 \\
5 \\
5 \\
5\end{array}$ & $\begin{array}{l}5 \\
5 \\
5 \\
5 \\
5 \\
5 \\
5 \\
5\end{array}$ & $\begin{array}{l}1.50 \\
1.31 \\
1.31 \\
1.31 \\
1.31 \\
1.05 \\
1.04 \\
1.04 \\
1.04 \\
1.04 \\
1.04 \\
1.04 \\
1.04\end{array}$ & $\begin{array}{l}3.8 \\
2.5 \\
1.2 \\
0.0 \\
0.0 \\
0.0 \\
0.0 \\
0.0 \\
0.0 \\
0.0\end{array}$ & $\begin{array}{l}1 \\
2 \\
2 \\
2 \\
2 \\
0\end{array}$ & $\begin{array}{l}1 \\
0 \\
3 \\
2 \\
2 \\
3 \\
1 \\
1 \\
1 \\
1\end{array}$ \\
\hline .5 & $\begin{array}{l}2 . \\
2 . \\
2 . \\
2 . \\
2 . \\
2 . \\
2 . \\
2 . \\
2 . \\
2 . \\
2 . \\
2 . \\
2 .\end{array}$ & $\begin{array}{r}0.00 \\
38.59 \\
89.45 \\
89.43 \\
89.42 \\
89.41 \\
89.40\end{array}$ & $\begin{array}{l}5 \\
5 \\
5 \\
5\end{array}$ & $\begin{array}{l}5 \\
5 \\
5 \\
5 \\
5 \\
5 \\
5\end{array}$ & $\begin{array}{l}1 \cdot 5 \\
1 \cdot 3 \\
1 \cdot 3 \\
1 \cdot 3 \\
1 \cdot 3 \\
1 \cdot 3 \\
1 \cdot 3 \\
1 \cdot 3 \\
1 \cdot 3 \\
1 \cdot 9 \\
1 \cdot 9 \\
1.5 \\
1.5\end{array}$ & $\begin{array}{l}3 . \\
4 . \\
3 . \\
2 . \\
0 . \\
0 . \\
0 . \\
0 . \\
0 . \\
0 . \\
0 .\end{array}$ & $\begin{array}{l}1 \\
2 \\
2 \\
2 \\
2 \\
7 \\
0 \\
0 \\
0\end{array}$ & $\begin{array}{l}27 \\
27 \\
27 \\
27 \\
2\end{array}$ \\
\hline & $\begin{array}{l}.000 \\
.000 \\
.000 \\
.000 \\
3.000\end{array}$ & $\begin{array}{r}0.00 \\
0.00 \\
89.44 \\
89.41 \\
89.40 \\
89.39\end{array}$ & $\begin{array}{l}.850 \\
.790 \\
.490 \\
.490 \\
.490 \\
.489\end{array}$ & $\begin{array}{l}\div 9 \\
\div 9 \\
\div 8\end{array}$ & $\begin{array}{l}1.5 \\
1.4 \\
1.3 \\
1.3 \\
1.3\end{array}$ & $\begin{array}{l}5.0 \\
5.1 \\
3.9 \\
2.7 \\
1.5\end{array}$ & $\begin{array}{l}0.004 \\
0.006 \\
0.006 \\
0.006 \\
0.003\end{array}$ & 7 \\
\hline
\end{tabular}




\begin{tabular}{|c|c|c|c|c|c|c|c|c|}
\hline $\begin{array}{l}1.500 \\
1.750 \\
2.000 \\
2.250 \\
2.500 \\
2.750 \\
3.000\end{array}$ & $\begin{array}{l}3.000 \\
3.000 \\
3.000 \\
3.000 \\
3.000 \\
3.000 \\
3.000\end{array}$ & $\begin{array}{l}89.38 \\
89.36 \\
89.38 \\
89.42 \\
89.41 \\
89.40 \\
89.40\end{array}$ & $\begin{array}{l}581.485 \\
581.472 \\
581.486 \\
581.509 \\
581.501 \\
581.500 \\
581.501\end{array}$ & $\begin{array}{l}581.485 \\
581.472 \\
581.485 \\
581.509 \\
581.501 \\
581.500 \\
581.501\end{array}$ & $\begin{array}{l}1.3138 \\
1.3137 \\
1.3138 \\
1.3140 \\
1.3139 \\
1.3139 \\
1.3139\end{array}$ & $\begin{array}{l}0.3760 \\
0.0000 \\
0.0000 \\
0.0000 \\
0.0000 \\
0.0000 \\
0.0000\end{array}$ & $\begin{array}{l}0.0010 \\
0.0000 \\
0.0000 \\
0.0000 \\
0.0000 \\
0.0000 \\
0.0000\end{array}$ & $\begin{array}{l}276.41 \\
276.32 \\
276.41 \\
276.57 \\
276.52 \\
276.51 \\
276.52\end{array}$ \\
\hline $\begin{array}{l}0.000 \\
0.250 \\
0.500 \\
0.750 \\
1.000 \\
1.250 \\
1.500 \\
1.750 \\
2.000 \\
2.250 \\
2.500 \\
2.750 \\
3.000\end{array}$ & $\begin{array}{l}4.000 \\
4.000 \\
4.000 \\
4.000 \\
4.000 \\
4.000 \\
4.000 \\
4.000 \\
4.000 \\
4.000 \\
4.000 \\
4.000 \\
4.000\end{array}$ & $\begin{array}{r}0.00 \\
0.00 \\
75.39 \\
89.41 \\
89.39 \\
89.39 \\
89.38 \\
89.36 \\
89.40 \\
89.55 \\
89.46 \\
89.39 \\
89.38\end{array}$ & $\begin{array}{l}671.850 \\
671.850 \\
581.503 \\
581.488 \\
581.488 \\
581.486 \\
581.484 \\
581.476 \\
581.496 \\
581.583 \\
581.533 \\
581.493 \\
581.489\end{array}$ & $\begin{array}{l}671.850 \\
671.850 \\
586.335 \\
581.488 \\
581.488 \\
581.486 \\
581.484 \\
581.476 \\
581.493 \\
581.582 \\
581.535 \\
581.494 \\
581.489\end{array}$ & $\begin{array}{l}1.5000 \\
1.5000 \\
1.3223 \\
1.3138 \\
1.3138 \\
1.3138 \\
1.3138 \\
1.3137 \\
1.3139 \\
1.3145 \\
1.3142 \\
1.3139 \\
1.3138\end{array}$ & $\begin{array}{l}5.0589 \\
5.0429 \\
5.6328 \\
4.5342 \\
3.3993 \\
2.2468 \\
1.0331 \\
0.0332 \\
0.0000 \\
0.0000 \\
0.0000 \\
0.0000 \\
0.0000\end{array}$ & $\begin{array}{l}0.0002 \\
0.0043 \\
0.0080 \\
0.0080 \\
0.0080 \\
0.0057 \\
0.0029 \\
0.0001 \\
0.0000 \\
0.0000 \\
0.0000 \\
0.0000 \\
0.0000\end{array}$ & $\begin{array}{l}217.66 \\
217.66 \\
270.27 \\
276.43 \\
276.43 \\
276.42 \\
276.40 \\
276.35 \\
276.47 \\
277.08 \\
276.76 \\
276.47 \\
276.44\end{array}$ \\
\hline $\begin{array}{l}0.000 \\
0.250 \\
0.500 \\
0.750 \\
1.000 \\
1.250 \\
1.500 \\
1.750 \\
2.000 \\
2.250 \\
2.500 \\
2.750 \\
3.000\end{array}$ & $\begin{array}{l}5.000 \\
5.000 \\
5.000 \\
5.000 \\
5.000 \\
5.000 \\
5.000 \\
5.000 \\
5.000 \\
5.000 \\
5.000 \\
5.000 \\
5.000\end{array}$ & $\begin{array}{r}0.00 \\
0.00 \\
0.00 \\
89.41 \\
89.39 \\
89.38 \\
89.38 \\
89.37 \\
89.34 \\
89.42 \\
89.45 \\
89.39 \\
89.38\end{array}$ & $\begin{array}{l}671.850 \\
671.850 \\
671.694 \\
581.488 \\
581.487 \\
581.486 \\
581.483 \\
581.478 \\
581.464 \\
581.507 \\
581.528 \\
581.495 \\
581.487\end{array}$ & $\begin{array}{l}671.850 \\
671.850 \\
671.745 \\
581.488 \\
581.487 \\
581.486 \\
581.483 \\
581.478 \\
581.464 \\
581.504 \\
581.529 \\
581.495 \\
581.487\end{array}$ & $\begin{array}{l}1.5000 \\
1.5000 \\
1.4998 \\
1.3138 \\
1.3138 \\
1.3138 \\
1.3138 \\
1.3138 \\
1.3137 \\
1.3139 \\
1.3141 \\
1.3139 \\
1.3138\end{array}$ & $\begin{array}{l}5.0589 \\
5.0429 \\
5.0291 \\
5.0902 \\
3.9878 \\
2.8702 \\
1.7021 \\
0.4914 \\
0.0000 \\
0.0000 \\
0.0000 \\
0.0000 \\
0.0000\end{array}$ & $\begin{array}{l}0.0002 \\
0.0044 \\
0.0082 \\
0.0098 \\
0.0098 \\
0.0076 \\
0.0049 \\
0.0015 \\
0.0000 \\
0.0000 \\
0.0000 \\
0.0000 \\
0.0000\end{array}$ & $\begin{array}{l}217.66 \\
217.66 \\
217.70 \\
276.43 \\
276.42 \\
276.41 \\
276.40 \\
276.36 \\
276.27 \\
276.54 \\
276.71 \\
276.48 \\
276.43\end{array}$ \\
\hline $\begin{array}{l}0.000 \\
0.250 \\
0.500 \\
0.750 \\
1.000 \\
1.250 \\
1.500 \\
1.750 \\
2.000 \\
2.250 \\
2.500 \\
2.750 \\
3.000\end{array}$ & $\begin{array}{l}6.000 \\
6.000 \\
6.000 \\
6.000 \\
6.000 \\
6.000 \\
6.000 \\
6.000 \\
6.000 \\
6.000 \\
6.000 \\
6.000 \\
6.000\end{array}$ & $\begin{array}{r}0.00 \\
0.00 \\
0.00 \\
85.54 \\
89.39 \\
89.38 \\
89.38 \\
89.37 \\
89.36 \\
89.39 \\
89.53 \\
89.44 \\
89.38\end{array}$ & 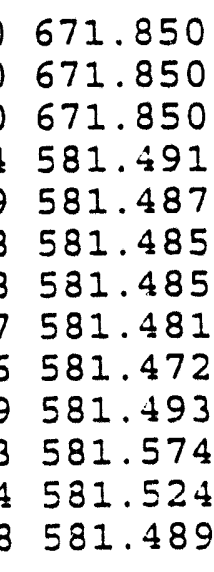 & $\begin{array}{l}671.850 \\
671.850 \\
671.850 \\
582.818 \\
581.487 \\
581.485 \\
581.485 \\
581.481 \\
581.472 \\
581.491 \\
581.573 \\
581.526 \\
581.489\end{array}$ & $\begin{array}{l}1.5000 \\
1.5000 \\
1.5000 \\
1.3162 \\
1.3138 \\
1.3138 \\
1.3138 \\
1.3138 \\
1.3137 \\
1.3138 \\
1.3144 \\
1.3141 \\
1.3138\end{array}$ & $\begin{array}{l}5.0589 \\
5.0429 \\
5.0283 \\
5.6008 \\
4.5372 \\
3.4500 \\
2.3191 \\
1.1227 \\
0.0851 \\
0.0000 \\
0.0000 \\
0.0000 \\
0.0000\end{array}$ & $\begin{array}{l}0.0003 \\
0.0044 \\
0.0083 \\
0.0115 \\
0.0115 \\
0.0094 \\
0.0068 \\
0.0034 \\
0.0003 \\
0.0000 \\
0.0000 \\
0.0000 \\
0.0000\end{array}$ & $\begin{array}{l}217.66 \\
217.66 \\
217.66 \\
274.77 \\
276.42 \\
276.41 \\
276.41 \\
276.38 \\
276.32 \\
276.45 \\
277.02 \\
276.69 \\
276.44\end{array}$ \\
\hline & 7.000 & & $\begin{array}{l}6 \\
0 \\
6\end{array}$ & 6 & $\begin{array}{l}00 \\
00\end{array}$ & & $\begin{array}{l}0.0003 \\
0.0044\end{array}$ & $\begin{array}{r}217 \\
217\end{array}$ \\
\hline
\end{tabular}


0.500

0.750

1.000

1.250

1. 500

1.750

2.000

2.250

2.500

2.750

3.000

0.000

0.250

0.500

0.750

1.000

1.250

1.500

1.750

2.000

2. 250

2.500

2.750

3.000

0.000

0.250

0.500

0.750

1.000

1. 250

1.500

1.750

2.000

2. 250

2. 500

2.750

3.000

0.00010 .000

$0.250 \quad 10.000$

0.50010 .000

$0.750 \quad 10.000$

1.00010 .000

1.25010 .000

1.50010 .000

1.75010 .000

2.00010 .000

2.25010 .000

$2 . \equiv 00 \quad 10.000$

2.75010 .000
$0.00 \quad 671.850 \quad 671.850 \quad 1.5000 \quad 5.0283 \quad 0.0083 \quad 217.66 \quad 8$ $0.00671 .543671 .642 \quad 1.4995 \quad 5.0162 \quad 0.0119 \quad 217.73 \quad 8$ $89.39581 .486 \quad 581.486 \quad 1.3138 \quad 5.0615 \quad 0.0132 \quad 276.424$ $89.38 \quad 581.486 \quad 581.486 \quad 1.3138 \quad 4.0014 \quad 0.0112 \quad 276.414$ $89.38 \quad 581.484 \quad 581.185 \quad 1.3138 \quad 2.9026 \quad 0.0086 \quad 276.414$ $89.37581 .482581 .482 \quad 1.31381 .74840 .0054276 .39=$ $89.36 \quad 581.475 \quad 581 . \$ 76 \quad 1.3137 \quad 0.5375 \quad 0.0017 \quad 276.353$ $89.35 \quad 581.468 \quad 581.467 \quad 1.3137 \quad 0.0000 \quad 0.0000 \quad 276.291$ $89.45 \quad 581.527 \quad 581.524 \quad 1.3141 \quad 0.0000 \quad 0.0000 \quad 276.68 \quad 1$ $89.47581 .540 \quad 581.541 \quad 1.3142 \quad 0.0000 \quad 0.0000 \quad 276.80 \quad 9$ $89.39581 .494 \quad 581.495 \quad 1.31390 .0000 \quad 0.0000 \quad 276.48 \quad 9$

$0.00 \quad 671.850 \quad 671.850 \quad 1.5000 \quad 5.0589 \quad 0.0003 \quad 217.668$ $0.00 \quad 671.850 \quad 671.850 \quad 1.5000 \quad 5.0429 \quad 0.0044 \quad 217.66 \quad 8$ $0.00 \quad 671.850 \quad 671.850 \quad 1.5000 \quad 5.0284 \quad 0.0083 \quad 217.66 \quad 8$ $0.00671 .850 \quad 671.850 \quad 1.5000 \quad 5.0147 \quad 0.0120 \quad 217.668$ $\begin{array}{lllllllll}88.33 & 581.489 & 581.855 & 1.3145 & 5.5581 & 0.0149 & 275.95 & 4\end{array}$ $89.38 \quad 581.486 \quad 581.486 \quad 1.3138 \quad 4.5253 \quad 0.0129 \quad 276.42 \quad 4$ $89.38 \quad 581.485 \quad 581.485 \quad 1.3138 \quad 3.4548 \quad 0.0104 \quad 276.414$ $89.38 \quad 581.484 \quad 581.484 \quad 1.3138 \quad 2.3359 \quad 0.0072 \quad 276.40 \quad 4$ $89.37581 .480 .581 .480 \quad 1.3138 \quad 1.1476 \quad 0.0036 \quad 276.384$ $89.35581 .470 \quad 581.470 \quad 1.3137 \quad 0.1014 \quad 0.0003 \quad 276.312$ $89.39581 .492581 .4891 .31380 .0000 \quad 0.0000 \quad 276.441$ $89.51581 .563 \quad 581.563 \quad 1.3143 \quad 0.0000 \quad 0.0000 \quad 276.95 \quad 1$ $89.43581 .516581 .5181 .3140 \quad 0.0000 \quad 0.0000 \quad 276.649$

$0.00 \quad 671.850 \quad 671.850 \quad 1.5000 \quad 5.0589 \quad 0.0004 \quad 217.66 \quad 8$ $0.00 \quad 671.850 \quad 671.850 \quad 1.5000 \quad 5.0430 \quad 0.0045 \quad 217.66 \quad 8$ $0.00 \quad 671.850 \quad 671.850 \quad 1.5000 \quad 5.0284 \quad 0.0083 \quad 217.66 \quad 8$ $\begin{array}{lllllllll}0.00 & 671.850 & 671.850 & 1.5000 & 5.0147 & 0.0120 & 217.66 & 8\end{array}$ $0.00 \quad 671.267 \quad 671.454 \quad 1.4991 \quad 5.0046 \quad 0.0154 \quad 217.798$ $89.39581 .486 \quad 581.486 \quad 1.3138 \quad 5.0224 \quad 0.0146 \quad 276.424$ $89.38 \quad 581.486 \quad 581.486 \quad 1.3138 \quad 3.9774 \quad 0.0121 \quad 276.414$ $89.38 \quad 581.484 \quad 581.484 \quad 1.3138 \quad 2.8891 \quad 0.0091 \quad 276.40 \quad 4$ $89.37581 .481 \quad 581.481 \quad 1.3138 \quad 1.7416 \quad 0.0056 \quad 276.394$ $89.36581 .474581 .4741 .3137 \quad 0.5356 \quad 0.0018 \quad 276.33 \quad 3$ $89.35 \quad 581.467581 .467 \quad 1.3137 \quad 0.0000 \quad 0.0000 \quad 270.281$ $89.45 \quad 581.527 \quad 581.525 \quad 1.3141 \quad 0.0000 \quad 0.0000 \quad 276.68 \quad 1$ $89.46581 .537581 .5381 .31420 .0000 \quad 0.0000 \quad 276.789$

$0.00671 .850 \quad 671.850 \quad 1.5000 \quad 5.0589 \quad 0.0004 \quad 217.668$ $0.00671 .850 \quad 671.850 \quad 1.5000 \quad 5.0430 \quad 0.0045 \quad 217.66 \quad 8$ $0.00671 .850 \quad 671.850 \quad 1.5000 \quad 5.0284 \quad 0.0084217 .66 \quad 8$ $0.00 \quad 671.850 \quad 671.350 \quad 1.5000 \quad 5.0147 \quad 0.0120 \quad 217.668$ $0.00671 .850 \quad 671.850 \quad 1.5000 \quad 5.0017 \quad 0.0155 \quad 217.668$ $89.09 \quad 581.488 \quad 581.589 \quad 1.3140 \quad 5.5054 \quad 0.0162 \quad 276.29 \quad 4$ $89.38 \quad 581.486 \quad 581.486 \quad 1.3138 \quad 4.4845 \quad 0.0138 \quad 276.414$ $89.38 \quad 581.485 \quad 581.485 \quad 1.3138 \quad 3.4235 \quad 0.0108 \quad 276.41 \div$ $89.38 \quad 581.483 \quad 581 . \div 83 \quad 1.3138 \quad 2.3103 \quad 0.0075 \quad 276.404$ $89.37581 .479581 .479 \quad 1.3138 \quad 1.1252 \quad 0.0037 \quad 276.374$ $89.3 \equiv 581.468 \quad \equiv 81 . \div 691.31370 .0900 \quad 0.0003 \quad 276.302$ $89.37581 .485 \quad 381 . \div 83 \quad 1.31380 .0000 \quad 0.0000 \quad 276.401$ 
$3.00010 .000 \quad 89.47581 .545 \quad 581 . \equiv 45 \quad 1.3142 \quad 0.0000 \quad 0.0000 \quad 276.821$

0.00011 .000

0.25011 .000

0.50011 .000

0.75011 .000

1.00011 .000

1.25011 .000

1.50011 .000

1.75011 .000

2.00011 .000

2.25011 .000

2.50011 .000

2.75011 .000

3.00011 .000

$0.000 \quad 12.000$

$0.250 \quad 12.000$

$0.500 \quad 12.000$

$0.750 \quad 12.000$

1.00012 .000

$1.250 \quad 12.000$

1.50012 .000

$1.750 \quad 12.000$

2.00012 .000

2. 25012.000

2.50012 .000

$2.750 \quad 12.000$

3.00012 .000

0.00013 .000

$0.250 \quad 13.000$

0.50013 .000

0.75013 .000

1.00013 .000

1.25013 .000

1.50013 .000

$1.750 \quad 13.000$

2.00013 .000

$2.250 \quad 13.000$

2.50013 .000

2.750 13.000

3.00013 .000

$0.000 \quad 14.000$

$0.250 \quad 14.000$

$0.500 \quad 14.000$

$0.750 \quad 14.000$

1.00014 .000

1. $250 \quad 14.000$

$1.500 \quad 14.000$

1.75014 .000
$0.00 \quad 671.850 \quad 671.850$

$0.00 \quad 671.850 \quad 671.850$

0.00671 .850

0.00671 .850

0.00671 .850

0.00

670.749

89.38

89.38

89.38

89.36

89.35

89.34

89.42

581.486

581.485

581.483

581.476

581.468

581.463

581.512

0.00671 .850

0.00671 .850

0.00671 .850

0.00671 .850

0.00

0.00

671.850

671.850

89.30

89.38

89.38

89.37

89.37

89.34

89.36

0.00

0.00

581.488

581.486

581.485

581.483

581.479

581.466

581.475

0.00

671.850

671.850

0.00

671.850

0.00

671.850

0.00

671.850

0.00

671.850

671.850

671.850

671.850

671.101

$581 . \div 86$

581.185

581.483

581.476

581.469

581.463

581.510

89.38

669.782

671.850

671.850

671.850

671.850

671.850

671.850

581.516

581.486

581.485

581.483

581.479

581.466

581.474

89.38

89.37

581.486

671.850

671.850

671.850

671.850

671.850

671.350

670.442

581.486

89.37

$581 . \div 84$

89.35

581.479

581.483

581.479

581.460

581.474

581.460
581.483

1.5000

1.5000

1.5000

1.5000

1.5000

1.4983

1.3138

1.3138

1. 3138

1.3137

1.3137

1.3137

1. 3140

1.5000

1.5000

1.5000

1.5000

1.5000

1.5000

1.3139

1.3138

1. 3138

1.3138

1.3138

1.3137

1.3137

1.5000

1.5000

1.5000

1.5000

1.5000

1.4969

1. 3138

I. 3138

1.3138

1.3138

1.3137

1.3136

0.00

671.850

671.850

1.5000

0.00

671.850

671.850

1.5000

0.00

671.850

671.850

1.5000

1.5000
1.5000

$671 . \equiv 50$

0.00

671.850

671.350

1. 5000

671.850

671.849

1.5000

0.00

581.487

581.495
5.0589

5.0430

5.0284

0.0004

0.0045

217.668

5.0148

0.0084

217.668

5.0018

0.0120

217.668

4.9948

4.9770

0.0155

217.66

3.9407

0.0169

217.668

2.8574

0.0155

217.918

1.7127

0.0126

276.42

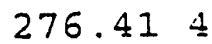

0.5120

0.0093

276.404

0.0000

0.0017

276.354

0.0000

.0000

276.303

276.261

5.0589

5.0430

5.0284

5.0148

5.0018

4.9893

5.4513

4.4378

3.3813

2.2705

1.0850

0.0679

0.0000

0.0045

0.0084

0.0121

0.0155

0.0169

0.0142276 .414

0.0111276 .414

0.0075276 .404

0.0036276 .374

0.0002276 .282

0.0000276 .331

89.36

5.0589

5.0430

5.0285

5.0148

5.0018

4.9893 
2.00014 .000

2. $250 \quad 14.000$

2.50014 .000

3.00014 .000

$0.000 \quad 15.000$

$0.250 \quad 15.000$

$0.500 \quad 15.000$

$0.750 \quad 15.000$

1.00015 .000

$1.250 \quad 15.000$

$1.500 \quad 15.000$

$1.750 \quad 15.000$

2.00015 .000

$2.250 \quad 15.000$

2.50015 .000

$2.750 \quad 15.000$

3.00015 .000

0.00016 .000

0.25016 .000

0.50016 .000

$0.750 \quad 16.000$

1.00016 .000

1.25016 .000

$1.500 \quad 16.000$

1.75016 .000

2.00016 .000

2. 25016.000

2.50016 .000

$2.750 \quad 16.000$

3.00016 .000

0.00017 .000

$0.250 \quad 17.000$

0.50017 .000

$0.750 \quad 17.000$

1.00017 .000

$1.250 \quad 17.000$

$1.500 \quad 17.000$

$1.750 \quad 17.000$

2.00017 .000

$2.250 \quad 17.000$

$2.500 \quad 17.000$

$2.750 \quad 17.000$

3.00017 .000
2.75014 .000

0.00018 .000
0.25018 .000
0.50018 .000
0.75018 .000

0.00018 .000
0.25018 .000
0.50018 .000
0.75018 .000

0.00018 .000
0.25018 .000
0.50018 .000
0.75018 .000

0.00018 .000
0.25018 .000
0.50018 .000
0.75018 .000

$89.38 \quad 581.485 \quad 581.485$

$89.38 \quad 581.484 \quad 581.484$

$89.37581 .482 \quad 581.482$

$89.36 \quad 581.477$

89.34581 .464

581.477

581.465

0.00671 .850

671.850

0.00671 .850

671.850

0.00671 .850

671.850

0.00

671.850

0.00

671.850

671.850

671.850

0.00

671.850

671.850

0.00

667.961

669.205

$89.38 \quad 581.486 \quad 581.486$

$89.38 \quad 581.485 \quad 581.485$

$89.38 \quad 581.485$

89.37581 .482

581.485

89.35

581.472

581.482

581.473

0.00

671.850.

671.850

671.850

1

1.3138

1. 3138

1.3138

1. 3138

1.3137

4.3902

3.3356

2.2245

1.0366

0.0414

$0.0145276 .41 \div$

0.0111276 .404

0.0075276 .394

$0.0035276 .36 \pm$

0.0001276 .272

0.00671 .850

671.850

1.5000

5.0589

0.0006

217.668

$0.00 \quad 671.850$

671.850

.5000

5.0430

0.0046

217.56

1.5000

5.0285

0.0085

217.66

1.50005 .0019

0.0121

0.0156

217.66

1.5000

4.9894

0.0170

1.4941

4.9770

1.3138

4.9843

0.0184

217.66

217.66

217.66

1.3138

4.8713

0.0161

218.52

1.3138

3.8408

0.0128

276.42

1. 3138

2. 7594

0.0093

276.41

1.3137

1.6124

0.0054

276.41

276.394

0.00671 .850

671.850

671.850

671.850

671.850

1.5000

0.0015

276.33

0.00671 .850

0.00

671.847

671.848

89.37581 .485

581.487

1.5000

5

0.0006217 .668

$89.38 \quad 581.486$

581.486

89.38

581.485

581.485

89.37

581.483

581.483

1.5000

5.0285

0.0047

217.668

89.36

581.478

581.478

1.5000

.0149

0.0122

0.0156

1.5000

4.9894

0.0170

1.5000

4.9770

1.3138

4.9648

0.0185

1.3138

5.3447

0.0177

1.3138

3.28 .16

0.0145

0.0110

1.3138

2.1688

0.0073

0.9774

0.0033

217.668

217.668

$217.66 \quad 8$

217.668

$0.00 \quad 671.850$

671.850

1.5000

5.0589

0.0006

0.00671 .850

671.850

1.5000

5.0431

0

0.00

671.850

671.850

1.5000

5.0286

0.00671 .850

671.850

1.5000

$0.00 \quad 671.850$

671.850

1.5000

5.0149

0.0047

0.00671 .850

671.850

1.5000

5.0020

0 .

0.0122

671.850

1.5000

4.9894

0.00671 .850

671.850

1.5000

4.9771

.0156

217.66

217.66

$0.00 \quad 664.506$

666.866

1.4889

4.9648

$89.38 \quad 581.486$

581.486

1.3138

4.9896

$89.38 \quad 581.486$

581.486

1.3138

4.8199

3.7893

89.37581 .485

581.485

1.3138

2.7064

89.37581 .481

581.481

1.3138

1.5565

0.0180

276.41

276.41

276.41

276.40

276.364

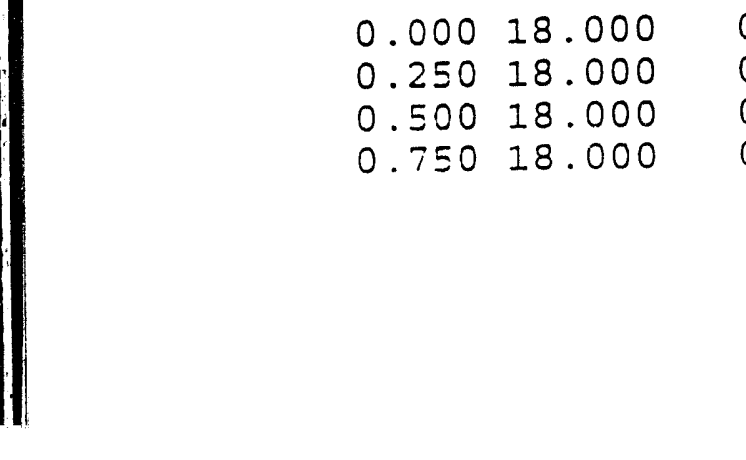

671.8501 .50005 .0589

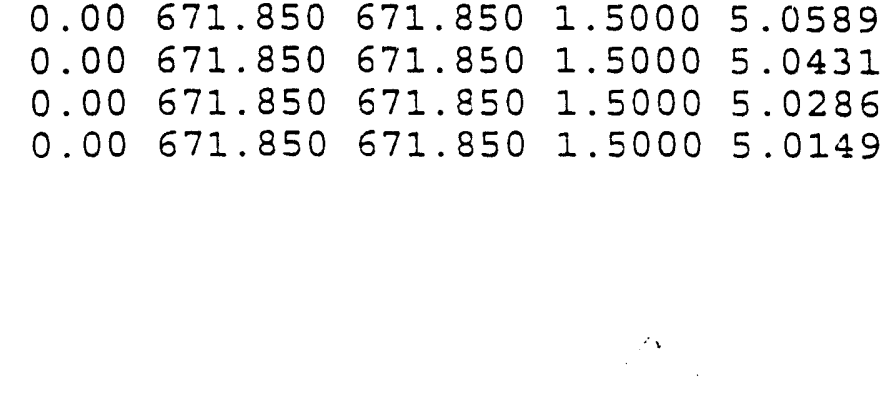


1.00018 .000

$1.250 \quad 18.000$

1.50018 .000

$1.750 \quad 18.000$

2.00018 .000

$2.250 \quad 18.000$

2.50018 .000

$2.750 \quad 18.000$

3.00018 .000

0.00019 .000

$0.250 \quad 19.000$

$0.500 \quad 19.000$

$0.750 \quad 19.000$

1.00019 .000

1.25019 .000

$1.500 \quad 19.000$

$1.750 \quad 19.000$

2.00019 .000

2.25019 .000

$2.500 \quad 19.000$

$2.750 \quad 19.000$

3.00019 .000

0.00020 .000

$0.250 \quad 20.000$

$0.500 \quad 20.000$

$0.750 \quad 20.000$

1.00020 .000

1.25020 .000

$1.500 \quad 20.000$

$1.750 \quad 20.000$

2.00020 .000

$2.250 \quad 20.000$

$2.500 \quad 20.000$

$2.750 \quad 20.000$

$3.000 \quad 20.000$

$0.000 \quad 20.799$

$0.250 \quad 20.799$

$0.500 \quad 20.799$

$0.750 \quad 20.799$

$1.000 \quad 20.799$

$1.250 \quad 20.799$

1.50020 .799

$1.750 \quad 20.799$

2.00020 .799

$2.250 \quad 20.799$

2.50020 .799

$2.750 \quad 20.799$

3.00020 .799
$0.00671 .850 \quad 671.850$

$0.00 \quad 671.850 \quad 671.850$

$0.00 \quad 671.850 \quad 671.850$

$0.00 \quad 671.850 \quad 671.850$

0.00671 .845671 .846

$89.38 \quad 581.486 \quad 581.487$

$89.38 \quad 581.485 \quad 581.485$

$89.37581 .484 \quad 581.484$

$89.37581 .482 \quad 581.482$

0.00671 .850671 .850

$0.00 \quad 671.850 \quad 671.850$

1.5000

5.0020

0.0156

217.668

$\begin{array}{llllll}1.5000 & 4.9895 & 0.0170 & 217.66 & 8\end{array}$

$\begin{array}{llllll}1.5000 & 4.9771 & 0.0180 & 217.66 & 8\end{array}$

$1.5000 \quad 4.9649 \quad 0.0185 \quad 217.66 \quad 8$

$1.5000 \quad 4.9527$

$0.0188 \quad 217.66 \quad 8$

$1.31385 .2908 \quad 0.0178 \quad 276.42 \div$

$1.31384 .28240 .0144276 .41 \div$

$1.31383 .22620 .0109276 .40 \div$

1.31382 .11100 .0072276 .39

$0.00 \quad 671.850671 .850$

1.5000

5.0589

0.0007

$217.66 \quad 8$

0.00671 .850

671.850

1.5000

5.0431

0.0047

217.668

0.00671 .850

671.850

1.5000

5.0286

0.0086

217.668

0.00671 .850

671.850

1.5000

5.0020

0.0122

217.668

0.00671 .850

671.850

1.5000

4.9895

0.0157

217.668

$0.00 \quad 671.850$

671.850

1.5000

4.9772

0.0170

217.668

0.00

671.850

671.850

1.5000

4.9649

0.0180217 .668

0.00

657.887

662.406

1.5000

4.9527

0.0185

217.668

89.38

$581.485=58$

1.4789

5.0108

0.0188

217.668

89.39

581.495

581.485

1.3138

4.7638

0.0190

220.778

89.37

581.482581 .482

1.3139

3.7318

0.0161276 .414

$0.00 \quad 671.850 \quad 671.850 \quad 1.5000 \quad 5.0589$

$0.00 \quad 671.850 \quad 671.850$

1.5000

0.00

671.850

671.850

1.5000

0.00

671.850

671.850

1.5000

0.00

671.850

671.850

1.5000

0

0.00

671.850

671.850

$0.00 \quad 671.850 \quad 671.850$

$0.00 \quad 671.850 \quad 671.850$

1.5000

1.5000

671.843

89.38581 .486

581.486

1.5000

1. 3138

1. 3138

$89.37581 .485 \quad 581.485$

1. 3138

0.00671 .850

0.00671 .850

0.00671 .850

0.00671 .850

0.00

671.850

671.850

1.5000

671.850

1.5000

5.0589

671.850

1.5000

671.850

1.5000

5.0431

0.0126

276.484

$0.00 \quad 671.850$

671.850

1.5000

5.0150

671.850

1.5000

5.0021

1.50004 .9896

4.9772

0.00

671.850

671.850

1.5000

4.9650

0.00

671.850

671.850

1.5000

4.9528

0.00

671.850

671.850

1.5000

4.9407

$-86.14$

581.906

642.870

1.5000

5.2207

0.0090

276.394

$89.38 \quad 581.486$

581.486

1. 3138

4.6927

$0.0007 \quad 217.66 \quad 8$

$89.37581 .486 \quad 581.486$

$1.3138 \quad 3.6591$

$0.0048 \quad 217.66 \quad 8$

0.0086217 .668

0.0122217 .668

0.0157217 .668

0.0171217 .668

0.0181217 .668

$0.0186217 .66 \quad 8$

$0.0188217 .66 \quad 8$

$0.0190 \quad 217.67 \quad 8$

0.0177276 .424

0.0143276 .424

0.0108276 .414

0.0007217 .668 0.0048217 .668

0.0086217 .668

$0.0123217 .66 \quad 8$

0.0157217 .668

0.0171217 .668

0.0181217 .668

$0.0186217 .66 \quad 8$

0.0189217 .668

0.0190217 .668

0.0193209 .397

0.0160276 .424

0.0125276 .414 
Run 10

MOVING BED REACTOR SIMULATION

Plant Cost Information

Design Variables $\times 1000$

Solid Sulfur Conc. Particle Diameter Gas Velocity Solid Velocity $0.01000 \quad 10.00000 \quad 1500.0000 \quad 6.00000$

Reactor length (X-direction). ( $f t)$
Reactor depth (Y-direction). (ft)

Reactor width (z-direction). (ft)

Percentage of $\mathrm{SO} 2$ removed. (\%)

Number of reactor units.

$\mathrm{SO} 2$ gas conc. at reactor inlet. (ppm)

Initial Solid sulfur conc. (lbmols/cuft)

Relative humidity at inlet.

Inlet gas temperature.

$(R)$

(\%)

Inlet solid/liquid temperature. (R)
Inlet superficial gas velocity. (ft/s)

Inlet superficial liquid velocity. (ft/s)

Sorbent superficial velocity. (ft/s)

Sorbent particle diameter. (ft)

Input flue gas flow rate. (acf/sec)

press. drop. (inch. H2O column)

Mesh size used in screen (mm)

Limestone mass flow rates:

Flowrate thru Feed Hopper \# 1. (1b/sec)

Flowrate thru Elevator \#4. (Ib/sec)

Flowrate thru storage Tank \#6. (1b/sec)

Flowrate thru Belt Conveyor \#8. (1b/sec)

Flowrate thru each Reactor $\# 9$. (Ib/sec)

Flowrate thru Belt Conveyor $\# 10$. (lb/sec)

Flowrate thru Belt Conveyor $\# 14$. ( $1 \mathrm{~b} / \mathrm{sec})$

Flowrate thru Belt Conveyor \#15.

( $1 \mathrm{~b} / \mathrm{sec})$

2.50 by 0.00100
18.37 by 0.00100
20.00

98.00

82.76

1107.

0.0000100

10.80

672.47

520.00

1.5000

0.0000000

0.00326

0.01000

44502.00

4.153

2.37894

2365.43

4411.19

2282.31

2282.31

27.58

2284.27

245.65

2045.76

20000.00

8216301.41

1370562.88

Mass of sorbent:

Sorbent in Feed Hopper \# 1. (Ib)

Sorbent in Storage Tank \# 6 . (1b)

Sorbent in Holding Bin $\# 11$. (1b)

64.4

Power Requirements:

Screw Feeder \# 2. (KW) 
Belt Conveyor \#3. (KN)

Bucket Elevator \#4. (KW)

Belt Conveyor \# 5. (KW)

Screw Feeder \# 7. (KW)

Belt Conveyor \# 8. (KW)

Belt Conveyor \# 10 . (KW)

Screw Feeder \#12. (KN)

Belt Conveyor \# 14. (KW)

Belt Conveyor \# 15. (KW)

I.D. Fan \# 16. (KW)

Humidification System \# 17. (KW)

Total power requirement. (KNh)

Total Cost of Power. (KS/Year)

Total Cost of Water. (K\$/Year)

Total Cost of Sorbent. (K\$/Year)

Total operating Cost. (K\$/Year)

Cost of Feed Hopper \#1. (KS)

Cost of Screw Feeder \#2. (K\$)

Cost of Belt Conveyor \# 3 . (KS)

Cost of Bucket Elevator \# 4 . (K\$)

Cost of Belt Conveyor \#5. (KS)

Cost of Storage Tank \#6. (KS)

Cost of Screw Feeder \# 7. (KS)

Cost of Belt Conveyor \# 8 . (KS)

Cost of Reactor Units $\# 9$. (KS)

Cost of Belt Conveyor $\# 10$. (KS)

Cost of Holding Bin $\doteq 11$. (KS)

Cost of Screw Feeder \#12. (KS)

Cost of Regenerator Units \# 13. (K\$)

Cost of Belt Conveyor \# 14. (KS)

Cost of Belt Conveyor $\# 15$. (XS)

Cost of I.D. Fan $\# 16$. (K\$)

Cost of Humidification system $\# 17$.

(K\$)

Total Fixed Cost. (K\$)

SYSTEM COST. (K\$/Year)
54.5

1184.7

101.6

81.2

87.7

87.8

71.4

5.7

32.4

277.2

100.0

2677.9

492.6

219.8

52217.4

52929.8

27.4

4.6

112.7

3588.7

112.7

1848.4

21.8

222.0

11450.2

222.0

527.7

13.7

493897.8

112.7

61.6

470.8

290.8

512985.6

140137.3 
Run 11

MOVING BED REACTOR SIMULATION

Plant Cost Information

Design Variables $\times 1000$

Solid Sulfur Conc. Particle Diameter Gas Velocity Solid Velocity $0.01000 \quad 10.00000 \quad 1500.0000 \quad 6.00000$

Reactor length (X-direction). ( $f t$ )

Reactor depth ( $Y$-direction). (ft)

Reactor width (z-direction). (ft)

Percentage of $\mathrm{SO} 2$ removed.

Number of reactor units.

SO2 gas conc. at reactor inlet. (ppm)

Initial solid sulfur conc. (lbmols/cuft)

Relative humidity at inlet.

Inlet gas temperature. (R)

Inlet solid/liquid temperature. (R)

Inlet superficial gas velocity. (ft/s)

Inler superficial Iiquid velocity.

Sorbent superficial velocity. (ft/s)

Sorbent particle diameter. ( $f t)$

Input flue gas flow rate. (acf/sec)

Press. drop. (inch. H2O column)

Mesh size used in screen (mm)

Limestone mass flow rates:

Elowrate thru Feed Hopper $\# 1$. ( $1 \mathrm{~b} / \mathrm{sec})$

Flowrace thru Elevator $\# 4$. (1b/sec)

Flowrate thru storage Tank \#6. (1b/sec)

Flowrate thru Belt Conveyor \# 8 . (1b/sec)

Flowrate thru each Reactor \# 9 . ( $1 \mathrm{~b} / \mathrm{sec}$ )

Flowrate thru Belt Conveyor $\# 10$. (lb/sec)

Flowrate thru Belt Conveyor $\neq 14$. ( $1 \mathrm{~b} / \mathrm{sec})$

Flowrate thru Belt Conveyor $\neq 15$.

(1b/sec)

Mass of sorbent:

Sorbent in Feed Hopper $\# 1$. (1b)

Sorient in Storage Tank $\# 6$. (lb)

Sorbent in Holding Bin $\# 11$. (1b)

Power Requirements:

Screw Feeder \#2. (KW)

2.50 by 0.00100
20.97 by 0.00100
20.00

90.00

72.74

1107.

0.0000100

10.80

672.47

520.00

1.5000

0.0000000

0.00326

0.01000

44502.00

4.153

2.35616

2121.27

3915.33

2006.18

2006.18

27.58

2007.99

217.91

1794.06

20000.00

7222256.21

1204792.42

57.7 
Belt Conveyor \# 3. (KW)

Bucket Elevator \#4. (KW)

Belt Conveyor \#5. (KW)

Screw Feeder \# 7. (KW)

Belt Conveyor $\neq 8$. (KW)

Belt Conveyor $\# 10$. (KW)

Screw Feeder \# $\#$ 12. (K'N)

Belt Conveyor $\# 14$. (KW)

Belt Conveyor $\# 15$. (KW)

I.D. Fan \# 16. (KW)

Humidification system \# 17.

(KW)

Total power requirement. (KWh)

48.9

1051.5

90.2

70.6

69.9

69.9

62.3

5.0

28.4

277.2

100.0

2401.4

Total cost of Power. (KS/Year)

Total Cost of water. (KS/Year)

Total Cost of Sorbent. (KS/Year)

441.8

219.8

46827.5

Total Operating Cost. (K\$/Year)

47489.0

Cost of Feed Hopper \# 1. (KS)

Cost of Screw Feeder \# 2. (K\$)

Cost of Belt Conveyor \# 3 . (K\$)

Cost of Bucket Elevator \# 4. (K\$)

Cost of Belt Conveyor \#5. (KS)

Cost of storage Tank \#6. (KS)

Cost of Screw Feeder \# 7 . (KS)

Cost of Belt Conveyor \# 8 . (KS)

Cost of Reactor Units \# 9 . (K\$)

Cost of Belt Conveyor \#10. (K\$)

Cost of Holding Bin \# 11. (K\$)

Cost of Screw Feeder \# 12. (K\$)

Cost of Regenerator Units \#13. (K\$)

Cost of Belt Conveyor \# $\#$. (KS)

Cost of Belt Conveyor \# 15 .
Cost of I.D. Fan \# 16 . (K\$)

27.4

4.6

112.7

3185.3

112.7

1688.9

21.0

196.4

10847.7

196.4

482.1

13.2

412049.1

112.7

61.6

472.7

290.8

Cost of HumidiEication System $\#: 7$.

(KS)

429875.3

Total Fixed Cost. (KS)

120567.8

SYSTEM COST. (KS/Year) 
Detailed Bed Conditions

\begin{tabular}{|c|c|c|c|c|c|c|c|c|}
\hline .000 & $\begin{array}{r}Y \\
.000 \\
.000\end{array}$ & $\begin{array}{l}\pi=56 \\
0.00 \\
0.00 \\
0.00 \\
0.00 \\
0.00 \\
0.00 \\
0.00 \\
0.00 \\
0.00 \\
0.00 \\
0.00\end{array}$ & $\begin{array}{r}\text { TL } \\
520.000 \\
520.000 \\
520.000 \\
520.000 \\
520.000 \\
520.000 \\
520.000 \\
520.000 \\
520.000 \\
520.000 \\
520.000\end{array}$ & $\begin{array}{r}\text { TG } \\
672.465 \\
520.000 \\
520.000 \\
520.000 \\
520.000 \\
520.000 \\
520.000\end{array}$ & $\begin{array}{l}\text { UG } \\
1.5000 \\
1.0458 \\
1.0458 \\
1.0458 \\
1.0458 \\
1.0458 \\
1.0458 \\
1.0458 \\
1.0458 \\
1.0458 \\
1.0458\end{array}$ & $\begin{array}{l}C S G * E 6 \\
2.2535 \\
1.6864 \\
0.0063 \\
0.0000 \\
0.0000 \\
0.0000 \\
0.0000 \\
0.0000 \\
0.0000 \\
0.0000\end{array}$ & $\begin{array}{l}\text { CSS } \\
0.0000 \\
0.0000 \\
0.0000 \\
0.0000 \\
0.0000 \\
0.0000 \\
0.0000 \\
0.0000 \\
0.0000 \\
0.0000 \\
0.0000\end{array}$ & $\begin{array}{r}\text { CWG*E6 } \\
220.98 \\
29.51 \\
29.51\end{array}$ \\
\hline $\begin{array}{l}\cdot \\
. \\
.\end{array}$ & $\dot{.}$ & $\begin{array}{l}0.00 \\
0.64 \\
0.57\end{array}$ & $\begin{array}{l}5 \\
5 \\
5 \\
5 \\
5 \\
5 \\
5 \\
5 \\
5 \\
5\end{array}$ & 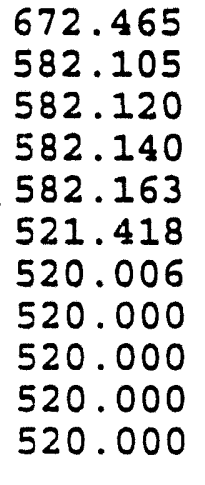 & $\begin{array}{l}1.5 \\
1.3 \\
1.3 \\
1.3 \\
1.3 \\
1.0 \\
1.9 \\
1.9 \\
1.9 \\
1.9 \\
1.0\end{array}$ & & & $\begin{array}{l}8 \\
2 \\
3 \\
7 \\
3 \\
5 \\
33 \\
1 \\
1 \\
1\end{array}$ \\
\hline & $\begin{array}{l}2 . \\
2 . \\
2 .\end{array}$ & $\begin{array}{l}0.00 \\
5.92 \\
0.47 \\
0.45 \\
0.44 \\
0.43 \\
0.42 \\
0.15 \\
0.62 \\
0.74\end{array}$ & $\begin{array}{l}8 \\
4 \\
9 \\
8 \\
8 \\
3\end{array}$ & $\begin{array}{l}6 \\
5 \\
5 \\
5 \\
5 \\
5 \\
5 \\
5 \\
5 \\
5 \\
5\end{array}$ & $\begin{array}{l}1 \cdot 5 \\
1 \cdot 3 \\
1 \cdot 3 \\
1 \cdot 3 \\
1 \cdot 3 \\
1.3 \\
1.3 \\
1.3 \\
1.2 \\
1.2 \\
1 .\end{array}$ & $\begin{array}{l}5 \\
7 \\
3 \\
0 \\
0 \\
0 \\
0 \\
0 \\
0 \\
0\end{array}$ & & \\
\hline 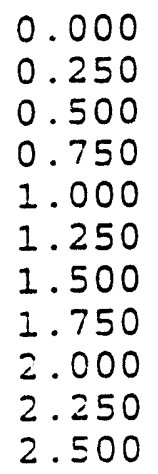 & $\begin{array}{l}3.000 \\
3.000 \\
3.000 \\
3.000 \\
3.000 \\
3.000 \\
3.000 \\
3.000 \\
3.000 \\
3.000\end{array}$ & $\begin{array}{r}0.00 \\
0.00 \\
90.46 \\
90.43 \\
90.42 \\
90.41 \\
90.40 \\
90.37 \\
90.38 \\
90.43 \\
90.43\end{array}$ & $\begin{array}{l}82.056 \\
82.055 \\
82.053 \\
82.049 \\
82.036 \\
82.040 \\
82.071 \\
82.068\end{array}$ & $\begin{array}{l}.4 \\
.4 \\
.0 \\
.0 \\
.0 \\
.0 \\
.0 \\
.0 \\
.0 \\
.0 \\
.0\end{array}$ & $\begin{array}{l}1.5 \\
1.4 \\
1.3 \\
1.3 \\
1.3 \\
1.3 \\
1.3 \\
1.3 \\
1.3 \\
1.3 \\
1.3\end{array}$ & $\begin{array}{l}2.2 \\
1.5 \\
0.5 \\
0.5 \\
0.1 \\
0.1 \\
0 . \\
0 . \\
0 . \\
0 .\end{array}$ & & $\begin{array}{l}2 \\
2 \\
2\end{array}$ \\
\hline
\end{tabular}


$\begin{array}{ll}0.000 & 4.000 \\ 0.250 & 4.000 \\ 0.500 & 4.000 \\ 0.750 & 4.000 \\ 1.000 & 4.000 \\ 1.250 & 4.000 \\ 1.500 & 4.000 \\ 1.750 & 4.000 \\ 2.000 & 4.000 \\ 2.250 & 4.000 \\ 2.500 & 4.000\end{array}$

0.000

0.250

0.500

0.750

1.000

1.250

1.500

1.750

2.000

2. 250

2.500

0.000

0.500

0.750

1.000

1.250

1.500

1.750

2.000

2.250

2.500

0.000

0.250

0.500

0.750

1.000

1.250

1.500

1.750

2.000

2. 250

2. 500

0.000

0.250

0.500

0.750

5.000

5.000

5.000

5.000

5.000

5.000

5.000

5.000

5.000

5.000

5.000

6.000

6.000

6.000

6.000

6.000

6.000

6.000

6.000

6.000

6.000

6.000

7.000
0.250
0.00672 .465

0.00672 .465

$79.48 \quad 582.064$

90.43

90.41

90.40

90.40

90.38

90.39

90.52

582.054

582.054

582.052

582.049

582.040

582.048

90.48

582.125

582.037

7.000

7.000

7.000

7.000

7.000

7.000

7.000

7.000

7.000

7.000

8.000

8.000

8.000

8.000

672.105
0.00672 .465

0.00672 .465

0.00672 .293

90.42582 .053

90.41582 .052

90.40582 .051

$90.40 \quad 582.049$

90.38582 .043

90.35582 .025

90.39582 .046

90.44

0.00

0.00

0.00

87.74

90.41

90.40

90.40

90.39

90.37

90.35

90.42

$0.00 \quad 672.465$

0.00

0.00

672.465

0.00

672.465

90.41

$90.40 \quad 582.052$

90.40

90.39

90.38

90.35

582.050

582.048

582.042

90.32

582.023

672.465

672.349

582.053

582.052

582.051

582.049

582.044

582.026

582.045

582.077

672.465

672.465

672.465

582.970

582.052

582.051

582.050

582.047

582.037

582.025

582.061

672.465

672.465

672.221

582.052

582.050

582.048

582.024
672.465
1.5000

1.5000

1.3205

1.3140

1.3140

1.3140

1.3140

1.3139

1.3140

1.3145

1.3143

1.5000

1.5000

1.4997

1.3140

1.3140

1.3140

1.3140

1.3140

1.3138

1.3140

1.3142

1.5000

1.5000

1.5000

1.3156

1.3140

1.3140

1.3140

1.3140

1.3139

1.3138

1.3141

1.5000

1.5000

2.2535

1.5000

2.2374

2.2227

2.2093

1.4995

1.7759

1.3140

0.5744

1.3140

0.0000

0.0000

1.3140

0.0000

1.31390

0.0000

1.3137

0.0000
672.465

0.0002220 .988

0.0043220 .988

$0.0073275 .47+$

$0.0042280 .36+$

$0.0006280 .36=$

$0.0000280 .35=$

$0.0000280 .33=$

0.0000280 .279

0.0000280 .319

0.0000280 .85

0.0000280 .689

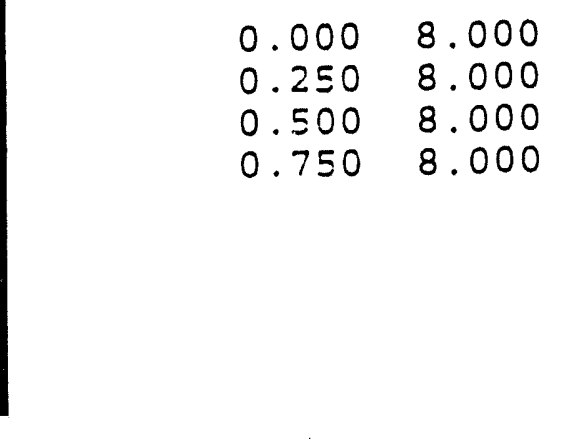

$0.00 \quad 672.465$

672.465

1.5000

2.2535

$0.0002220 .98 \varepsilon$

0.0044220 .988

0.0076221 .028

0.0061280 .354

0.0022280 .353

0.0000280 .341

0.0000280 .331

0.0000280 .291

0.0000280 .179

0.0000280 .309

0.00672 .465

672.465

1.5000

2.2374

0.00672 .465

672.465

1.5000

2.2227

0.00672 .465

672.465
1.5000
$0.0003220 .98 \quad 8$

0.0045

220.988

0.0003220 .988

0.0044220 .988

0.0076220 .988

0.0079279 .184

0.0041280 .354

0.0005280 .342

0.0000280 .341

0.0000280 .311

0.0000280 .169

0.0000280 .419

$0.0003220 .98 \varepsilon$ $0.0044220 .98 \quad 8$ 0.0076220 .988 0.0084221 .068 0.0061280 .354 0.0020280 .353 0.0000280 .341 0.0000280 .321 0.0000280 .281 0.0000280 .159 0.0000280 .019

$0.0077220 .98 \quad 8$ 0.0084220 .988
0.0000280 .249 


\begin{tabular}{|c|c|c|c|c|c|c|c|c|c|}
\hline .2 & $\begin{array}{l}8 . \\
8 . \\
8 . \\
8 . \\
8 . \\
8 .\end{array}$ & 78 & 2 . & $\begin{array}{l}5 \\
5 \\
5 \\
5 \\
5\end{array}$ & $\begin{array}{l}4 \\
0 \\
0 \\
0 \\
0\end{array}$ & $\begin{array}{l}3 \\
5 \\
1 \\
0 \\
0 \\
0 \\
0\end{array}$ & & $\begin{array}{l}9 \\
5 \\
4 \\
3 \\
1 \\
2 \\
8\end{array}$ & 4 \\
\hline 7 & $\begin{array}{l}9 . \\
9 . \\
9 . \\
9 . \\
9 . \\
9 . \\
9 . \\
9 .\end{array}$ & $\begin{array}{l}0.00 \\
0.00 \\
0.00 \\
0.00 \\
0.00 \\
90.40 \\
90.40 \\
90.40 \\
90.39 \\
90.37 \\
90.35\end{array}$ & $\begin{array}{l}672.465 \\
672.465 \\
672.465 \\
672.465 \\
671.725 \\
582.052 \\
582.051 \\
582.050 \\
582.047 \\
582.034 \\
582.021\end{array}$ & $\begin{array}{l}67 \\
67 \\
67 \\
67 \\
67 \\
58 \\
58 \\
58 \\
58 \\
58 \\
5\end{array}$ & $\begin{array}{l}1 \cdot 5 \\
1.5 \\
1.5 \\
1.2 \\
1.2 \\
1.2 \\
1.2\end{array}$ & $\begin{array}{l}2.2 \\
2.2 \\
2.2 \\
2.2 \\
2.1 \\
1.2 \\
0.5 \\
0.0 \\
0.0 \\
0.0 \\
0.0\end{array}$ & $\begin{array}{l}0 \\
0 \\
0 \\
0 \\
0 \\
0 \\
0 \\
0 \\
0 \\
0 \\
0\end{array}$ & 0 & \\
\hline $\begin{array}{l}00 \\
50\end{array}$ & $\begin{array}{l}10 . \\
10 . \\
10 . \\
10 . \\
10 . \\
10 . \\
10 . \\
10 . \\
10 .\end{array}$ & $\begin{array}{r}0 . \\
0 \\
0 . \\
0 \\
0 \\
90 \\
90 \\
90 \\
90\end{array}$ & $\begin{array}{l}672.4 \\
672.4 \\
672.4 \\
672.4 \\
672.4 \\
582.0 \\
582.0 \\
582.0 \\
582.0 \\
582.0 \\
582.0\end{array}$ & $\begin{array}{l}67 \\
67 \\
67 \\
67 \\
67 \\
58 \\
58 \\
58 \\
58 \\
58\end{array}$ & $\begin{array}{l}1 \\
1 \\
1 \\
1\end{array}$ & $\begin{array}{l}2 . \\
2 . \\
2 . \\
1 . \\
0 . \\
0 . \\
0 . \\
0 .\end{array}$ & $\begin{array}{l}0 \\
0 \\
0 \\
0 \\
0 \\
0 \\
0 \\
0\end{array}$ & $\begin{array}{l}220 . \\
220 . \\
220 . \\
220 . \\
220 . \\
280 . \\
280 . \\
280 . \\
280 . \\
280 . \\
280 .\end{array}$ & \\
\hline $\begin{array}{l}0 \\
0 \\
0 \\
0 \\
0 \\
0 \\
0\end{array}$ & $\begin{array}{l}11.0 \\
11.0 \\
11.0 \\
11.0 \\
11.0 \\
11.0 \\
11.0 \\
11.0 \\
11.0 \\
11.0 \\
11.0\end{array}$ & $\begin{array}{l}0 . \\
0 . \\
0 . \\
0 . \\
0 . \\
0 . \\
90 . \\
90 . \\
90 . \\
90 . \\
90 .\end{array}$ & $\begin{array}{l}6 \\
6 \\
6 \\
6 \\
6 \\
6 \\
6 \\
5 \\
5 \\
5 \\
5\end{array}$ & $\begin{array}{l}67 \\
67 \\
67 \\
67 \\
67 \\
67 \\
58 \\
58 \\
58 \\
58 \\
58\end{array}$ & $\begin{array}{l}0 \\
0 \\
0 \\
0 \\
0 \\
7 \\
0 \\
0 \\
0 \\
0\end{array}$ & $\begin{array}{l}2 \\
2 \\
1 \\
0 \\
0 \\
0\end{array}$ & $\begin{array}{l}4 \\
5 \\
7 \\
5 \\
6 \\
6 \\
6 \\
6 \\
0 \\
0 \\
0\end{array}$ & $\begin{array}{l}2 \\
2 \\
2 \\
2 \\
2 \\
2 \\
2 \\
2 \\
2 \\
2\end{array}$ & \\
\hline $\begin{array}{l}50 \\
50 \\
50 \\
0\end{array}$ & $\begin{array}{l}12.000 \\
12.000 \\
12.000 \\
12.000 \\
12.000 \\
12.000 \\
12.000\end{array}$ & $\begin{array}{l}0 \\
0 \\
0 \\
0 \\
0 \\
0 \\
0\end{array}$ & $\begin{array}{l}6 \\
6 \\
6 \\
6 \\
6 \\
6 \\
5\end{array}$ & $\begin{array}{l}6 \\
6 \\
6 \\
6 \\
6 \\
6 \\
5\end{array}$ & $\begin{array}{l}1 . \\
1 . \\
1 . \\
1 . \\
1 . \\
1 .\end{array}$ & $\begin{array}{l}2 . \\
2 . \\
2 . \\
2 . \\
2 . \\
2 . \\
2 .\end{array}$ & $\begin{array}{l}0 . \\
0 . \\
0 . \\
0 . \\
0 . \\
0 . \\
0 . \\
0 .\end{array}$ & $\begin{array}{ll}2 \\
5 \\
5 \\
5 \\
5 \\
5 \\
5\end{array}$ & \\
\hline
\end{tabular}


2.00012 .000

$2.250 \quad 12.000$

2.50012 .000

0.00013 .000

0.25013 .000

0.50013 .000

$0.750 \quad 13.000$

1.00013 .000

$1.250 \quad 13.000$

$1.500 \quad 13.000$

$1.750 \quad 13.000$

2.00013 .000

2.25013 .000

$2.500 \quad 13.000$

0.00014 .000

0.25014 .000

0.50014 .000

0.75014 .000

1.00014 .000

$1.250 \quad 14.000$

$1.500 \quad 14.000$

$1.750 \quad 14.000$

2.00014 .000

$2.250 \quad 14.000$

2.50014 .000

$0.000 \quad 15.000$

$0.250 \quad 15.000$

0.50015 .000

0.75015 .000

1.00015 .000

$1.250 \quad 15.000$

$1.500 \quad 15.000$

$1.750 \quad 15.000$

$2.000 \quad 15.000$

2.25015 .000

$2.500 \quad 15.000$

0.00016 .000

0.25016 .000

0.50016 .000

0.75016 .000

1.00016 .000

$1.250 \quad 16.000$

1.50016 .000

1.75016 .000

2.00016 .000

$2.250 \quad 16.000$

2.50016 .000
$90.40 \quad 582.051$

90.39582 .050

90.39582 .047

0.00672 .465

0.00672 .465

$0.00 \quad 672.465$

0.00672 .465

$0.00 \quad 672.465$

$0.00 \quad 672.465$

$0.00 \quad 669.320$

$90.40 \quad 582.052$

$90.40 \quad 582.051$

90.39582 .047

90.39582 .049

$0.00 \quad 672.465$

0.00672 .465

$0.00 \quad 672.465$

0.00672 .465

0.00672 .465

0.00672 .465

0.00672 .463

90.39582 .052

$90.40 \quad 582.051$

$90.40 \quad 582.051$

90.39582 .049

$0.00 \quad 672.465$

$0.00 \quad 672.465$

0.00672 .465

$0.00 \quad 672.465$

$0.00 \quad 672.465$

$0.00 \quad 672.465$

$0.00 \quad 672.465$

0.00666 .055

90.40582 .051

90.39582 .048

90.39582 .045

$0.00 \quad 672.465$

$0.00 \quad 672.465$

$0.00 \quad 672.465$

0.00672 .465

$0.00 \quad 672.465$

$0.00 \quad 672.465$

$0.00 \quad 672.465$

0.00

672.460

672.465

672.465

672.465

672.465

672.465

672.465

672.464

582.055

582.051

582.051

582.049

672.465

672.465

672.465

672.465

672.465

672.465

$672 . \pm 65$

668.129

$\$ 82.051$

582.049

582.045

1.5000

1.5000

1.5000

1.5000

1.5000

1.5000

1.5000

1.4903

1.3140

1.3140

1. 3140

672.465

672.465

1.5000

672.465

1.5000

672.465

1.5000

672.465

1.5000

1.5000

672.465

1.5000

672.465

1.5000

$672 . \div 62$

1.5000

90.40

90.40

90.40
582.052582 .053

1. 3140

582.051

582.050
1. 3140

1.3140
0.0228

0.0001280 .341 0.0000280 .331 $0 \quad 0.0000280 .311$

0.0000

$\begin{array}{llll}2.2535 & 0.0005 & 220.98 \quad 8\end{array}$

$\begin{array}{llll}2.2375 & 0.0046 & 220.98 \quad 8\end{array}$

$\begin{array}{lllll}2.2228 & 0.0078 & 220.98 & 8\end{array}$

$2.2087 \quad 0.0086220 .98 \quad 8$

$\begin{array}{llll}2.1946 & 0.0087 & 220.98 \quad 8\end{array}$

$\begin{array}{llll}2.1805 & 0.0086 & 220.98 & 8\end{array}$

$\begin{array}{llll}2.1733 & 0.0085 & 221.68 & 8\end{array}$

$\begin{array}{lll}1.5592 & 0.0054 & 280.35\end{array}$

$\begin{array}{lllll}0.3908 & 0.0014 & 280.34 & 3\end{array}$

$0.0000 \quad 0.0000 \quad 280.321$

$0.0000 \quad 0.0000280 .331$

2.25350 .0005220 .988

$\begin{array}{lllll}0 & 2.2375 & 0.0046 & 220.98 & 8\end{array}$

$\begin{array}{lllll}0.2229 & 0.0078 & 220.98 & 8\end{array}$

$\begin{array}{lllll}2.2087 & 0.0086 & 220.98 & 8\end{array}$

$\begin{array}{lllll}2.1946 & 0.0087 & 220.98 & 8\end{array}$

$\begin{array}{lllll}0 & 2.1806 & 0.0086 & 220.98 & 8\end{array}$

$\begin{array}{llllll}0 & 2.1665 & 0.0085 & 220.98 & 8\end{array}$

$\begin{array}{lllll}2.1095 & 0.0073 & 280.35 & 4\end{array}$

$\begin{array}{llllll}0.9153 & 0.0032 & 280.34 & 4\end{array}$

$0.0062 \quad 0.0000280 .341$

$0.0000 \quad 0.0000280 .331$

$2.25350 .0006 \quad 220.98 \quad 8$

$2.2375 \quad 0.0046 \quad 220.98 \quad 8$

$\begin{array}{lllll}2.2229 & 0.0078 & 220.98 & 8\end{array}$

$\begin{array}{lllll}2.2087 & 0.0086 & 220.98 & 8\end{array}$

$\begin{array}{lllll}2.1947 & 0.0087 & 220.98 & 8\end{array}$

$\begin{array}{lllll}2.1806 & 0.0087 & 220.98 & 8\end{array}$

$\begin{array}{llll}2.1665 & 0.0086 & 220.98 & 8\end{array}$

$\begin{array}{llll}2.1663 & 0.0085 & 222.418\end{array}$

$\begin{array}{llll}1.4902 & 0.0051 & 280.34 & 4\end{array}$

$\begin{array}{llll}0.3373 & 0.0012 & 280.332\end{array}$

$0.0000 \quad 0.0000280 .301$

$2.2535 \quad 0.0006 \quad 220.98 \quad 8$

$\begin{array}{lllll}2.2375 & 0.0047 & 220.98 & 8\end{array}$

$\begin{array}{llll}2.2229 & 0.0079 & 220.98 & 8\end{array}$

$\begin{array}{lllll}2.2088 & 0.0086 & 220.98 & 8\end{array}$

$\begin{array}{llll}2.1947 & 0.0088 & 220.98 & 8\end{array}$

$\begin{array}{lllll}2.1806 & 0.0087 & 220.98 & 8\end{array}$

$\begin{array}{llll}2.1666 & 0.0086 & 220.98 & 8\end{array}$

$\begin{array}{llll}2.1525 & 0.0085 & 220.98 & 8\end{array}$

2.04090 .0070280 .354

$0.8405 \quad 0.0029280 .34$

0.00170 .0000280 .341 
0.00017 .000

0.25017 .000

0.50017 .000

0.75017 .000

1.00017 .000

1.25017 .000

$1.500 \quad 17.000$

$1.750 \quad 17.000$

2.00017 .000

$2.250 \quad 17.000$

$2.500 \quad 17.000$

0.00018 .000

0.25018 .000

0.50018 .000

0.75018 .000

1.00018 .000

1.25018 .000

1.50018 .000

1.75018 .000

2.00018 .000

2.25018 .000

$2.500 \quad 18.000$

0.00019 .000

$0.250 \quad 19.000$

$0.500 \quad 19.000$

$0.750 \quad 19.000$

1.00019 .000

$1.250 \quad 19.000$

1.50019 .000

$1.750 \quad 19.000$

2.00019 .000

$2.250 \quad 19.000$

2.50019 .000

0.00020 .000

0.25020 .000

0.50020 .000

$0.750 \quad 20.000$

1.00020 .000

$1.250 \quad 20.000$

$1.500 \quad 20.000$

$1.750 \quad 20.000$

2.00020 .000

2. $250 \quad 20.000$

2.50020 .000

0.00020 .968

$0.250 \quad 20.968$

$0.500 \quad 20.968$

$0.750 \quad 20.968$
0.00

0.00

0.00

0.00

0.00

0.00

0.00

0.00

0.00

90.40

90.40

0.00

0.00

0.00

0.00

0.00

0.00

0.00

0.00

0.00
90.40

90.40

$0.00 \quad 672.465$

0.00672 .465

$0.00 \quad 672.465$

$0.00 \quad 672.465$

$0.00 \quad 672.465$

0.00672 .465

$0.00 \quad 672.465$

$0.00 \quad 672.465$

$0.00 \quad 672.465$

$0.00 \quad 645.195$

$90.40 \quad 582.051$

$0.00 \quad 672.465$

0.00

672.465

$0.00 \quad 672.465$

$0.00 \quad 672.465$

0.00672 .465

0.00

672.465

0.00

672.465

0.00

672.465

0.00

672.465

0.00

90.40

672.445

582.053

0.00672 .465

$0.00 \quad 672.465$

$0.00 \quad 672.465$

0.00672 .465
672.465

672.465

672.465

672.465

672.465

672.465

672.465

672.465

653.659

582.052

582.051

672.465

672.465

672.465

672.465

672.465

672.465

672.465

672.465

672.459

582.052

582.051

672.465

672.465

672.465

672.465

672.465

672.465

672.465

672.465

672.465

654.193

582.051

672.465

672.465

672.465

672.165

672.465

672.465

672.465

672.465

672.465

672.452

582.053

672.465

672.165

672.465

$672 . \div 65$
1.5000

2.2535

1.5000

2.2375

1.5000

2.2229

1.5000

2.2088

$1.5000 \quad 2.1947$

$1.5000 \quad 2.1807$

1.50002 .1666

1.50002 .1525

1.48042 .1666

1.31401 .4166

1.31400 .2836

$1.5000 \quad 2.2535$

1.50002 .2375

1.5000

2.2229

1.5000

2.2088

1.5000

2.1948

1.5000

2.1807

1.5000

2.1667

1.5000

2.1526

1.5000

2.1385

1.3140

1.9699

1.3140

0.7649

1.50002 .2535

1.50002 .2376

1.50002 .2230

1.50002 .2088

1.50002 .1948

1.50002 .1808

1.50002 .1667

1.5000

1.4592

2.1526

2.1385

2.1833

1.3427

1.5000

2.2535

1.5000

2.2376

1.5000

2.2230

1.5000

2.2089

1.5000

2.1948

1.50002 .1808

1.50002 .1667

$1.5000 \quad 2.1527$

1.50002 .1386

1.50002 .1245

1.31401 .8985

0.0006

0.0047

0.0079

0.0087

c. 00088

0.0087

0.0086

0.0085

0.0084

0.0068

0.0026

0.0007

0.0048

0.0080

0.0087

0.0088

0.0088

0.0087

0.0086

0.0085

0.0083

0.0046

220.988

220.983

220.988

220.988

220.988

220.988

220.988

220.988

220.988

280.354

280.343

0.0007220 .988

$0.0048 \quad 220.98 \quad 8$

$0.0080220 .98 \quad 8$

$0.0088220 .98 \quad 8$

$0.0089220 .98 \quad 8$

$0.0088220 .98 \quad 8$

$0.0087220 .98 \quad 8$

$0.0086220 .98 \quad 8$

0.0085220 .988

0.0084220 .988

0.0065280 .364

1.50002 .2535

$0.0007220 .98 \quad 8$

1.50002 .2376

$0.0048220 .98 \quad 8$

1.50002 .2230

$0.0080 \quad 220.98 \quad 8$

$0.0088220 .98 \quad 8$ 


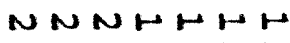

in $i, 0$ in in

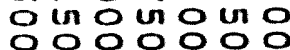

NNNNNNN

- io io io io

10 เด

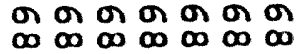

0000000 0000000 0000000

on on on on on on ONNNNNN

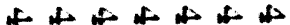
क o क क क क क (I) Un Ul UI In UI or or oi or on on or

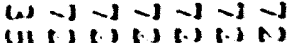
iv

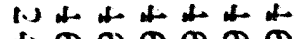
क on of or on on or

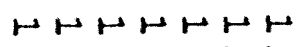
t. un ui un un un in 1 000000

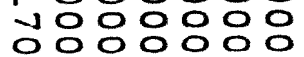
NHNNNNN is is is is wi $\omega$ ⿰

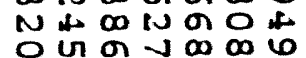
0000000 잉ㅇㅇㅇㅇㅇㅇㅇㅇ ( wi u o NNNNNNN WNNNNNN WOOOOOO $\infty 6106666$ $\mapsto \infty \infty \infty \infty \infty$

(s) 0000000 
